\title{
Discography as A Diagnostic Test For Spinal Pain: A Systematic and Narrative ReVIEW
}

\author{
Rinoo V. Shah, MD, Clifford R. Everett, MD, Anne Marie McKenzie-Brown, MD, and Nalini Sehgal, MD
}

Background: The intervertebral disc has been implicated as an etiology of chronic spine pain based on clinical, basic science, and epidemiological research. Unfortunately, there is no way to determine with absolute certainty whether or not the disc is a spinal pain generator. Recent advances in the neurobiology of pain processing further underscore the possibility that we may never know the source of a patient's pain. At our current level of understanding, from an empirical standpoint, discography is thought of as the best tool to evaluate disc-related pain.

Study Design: A systematic review

Objectives: To systematically assess the quality of clinical studies evaluating the diagnostic accuracy of discography with re- spect to chronic spinal pain.

Methods: A systematic review of the literature was performed to assess the diagnostic accuracy of discography with respect to chronic spinal pain. Study inclusion/ exclusion criteria were based on the mod ern practice of discography. Selected studies were then subjected to two rating instruments for diagnostic accuracy studies (AHRQ and QUADAS). Specific data were then culled from these studies and tabulated. Evidence was then classified into five levels: conclusive, strong, moderate, limited, or indeterminate.

Results: Evidence is strong for the diagnostic accuracy of discography as an imaging tool. Evidence is also strong for the ability of discography to evoke pain. There is strong evidence supporting the role of discography in identifying that subset of patients with lumbar discogenic pain. There is moderate evidence supporting the role of discography in identifying a subset of patients with cervical discogenic pain. There is limited evidence supporting the role of discography in identifying a subset of patients with thoracic discogenic pain.

Conclusion: Discography is a useful imaging and pain evaluation tool in identifying a subset of patients with chronic spinal pain secondary to intervertebral disc disorders.

Keywords: Spinal pain, intervertebral disc, discography, pain generator, false-positives, diagnostic accuracy
Discography was mainly used as an imaging tool, in the past (1-5) and is considered to be superior to radiographs, myelography, and CT-scanning, in imaging intervertertebral disc (IVD) morphology (6). Discography is comparable to MR imaging in detecting degenerative disc disease (DDD) but is inferior in detecting disc protrusions (HNP) (7-11). The ability of discography to image the IVD has been validated by direct cadaveric and intra-operative examinations (12-16) and may be improved by using thin slice CT-scanning $(6,9,17-21)$. Some authors tout the merits of knowing about IVD morphology via

From Texas Tech University, Lubbock, TX; University of Rochester Medical Center, Rochester, NY; Emory Department of Anesthesiology, Emory Center for Pain Medicine, Atlanta, GA; and University of Wisconsin Hospital \& Clinics, Madison, WI.

Address Correspondence:

Rinoo V. Shah, MD, International Pain Institute, Texas Tech University Health Services Center 4430 South Loop 289, Lubbock, TX 79414

Disclaimer: Nothing of monetary value was received in the preparation of this manuscript.

Conflict of Interest: None

Acknowledgement:

Manuscript received on3/7/2005

Revision submitted on 3/20/2005

Accepted for publication on $3 / 22 / 2005$ discography (17).

Nonetheless, concerns about invasiveness, radiation exposure, infectious risk, and the routine availability of CT/ MR imaging have minimized the role of discography, as an imaging only tool (22). Furthermore, knowing IVD morphology, in isolation, may not be useful. DDD occurs due to age-related and genetic factors (23-26) and occurs with a similar frequency in symptomatic and asymptomatic patients (7). DDD is not necessarily painful and even then, the pain may be dissimilar (27). Although some authors (28) report increased pain with DDD, careful inspection of their data demonstrates that concordant pain occurs in a small fraction of patients. Conversely, DDD will not predict whether a disc is painful in a particular patient (28). In the case of annular disruption, the side of annular tear may not correspond to the side of a patient's pain (29). Discograms do not image pain and hence, do not provide insight into which neural pathways mediate discogenic pain (30-35). IVD morphology should not change within a short interval, but discographic images may change, after only two weeks - technical errors account for only a small portion of these changes (36).

Whereas discographic imaging alone may not be useful, pain provocation in combination with real time imaging may be useful. Pain provocation, actually, dominates modern discographic practice and is used clinically. An integrative imaging approach, which incorporates provocative discography, may best select patients for intradiscal therapies (37-40).

So why perform a systematic review of discography? Systematic reviews of diagnostic test studies aim to identify and evaluate peer-reviewed medical research pertaining to diagnostic test accuracy. The quality assessment of diagnostic accuracy studies differs from that of standard intervention studies. To measure diagnostic accuracy, one must compare the test to the criterion standard. Since there is no criterion standard, a systematic review of the discography literature is challenging. This systematic review evaluates those studies that specifically examine the ability of discography, as a pain-provoking and imaging tool, to diagnose discogenic pain. This systematic review was performed to determine whether discography is a useful test in the diagnostic evaluation of patients 
Table 1. Domains and elements for diagnostic studies developed by the Agency for Healthcare Research and Quality (AHRQ)

\begin{tabular}{|c|c|}
\hline Domain $^{\#}$ & Elements $^{*}$ \\
\hline Study Population & $\begin{array}{l}\text { - Subjects similar to populations in which the test would be } \\
\text { used and with a similar spectrum of disease }\end{array}$ \\
\hline Adequate Description of Test & $\begin{array}{l}\text { - Details of test and its administration sufficient to allow } \\
\text { for replication of study }\end{array}$ \\
\hline $\begin{array}{l}\text { Appropriate Reference } \\
\text { Standard }\end{array}$ & $\begin{array}{l}\text { - Appropriate reference standard (“gold standard”) used for } \\
\text { comparison } \\
\text { - Reference standard reproducible }\end{array}$ \\
\hline $\begin{array}{l}\text { Blinded Comparison of Test } \\
\text { and Reference }\end{array}$ & $\begin{array}{l}\text { - Evaluation of test without knowledge of disease status, if } \\
\text { possible }\end{array}$ \\
\hline & - Independent, blind interpretation of test and reference \\
\hline $\begin{array}{l}\text { Avoidance of Verification } \\
\text { Bias }\end{array}$ & $\begin{array}{l}\text { - Decision to perform reference standard not dependent on } \\
\text { results of test under study }\end{array}$ \\
\hline
\end{tabular}

${ }^{*}$ Key domains are in italics

${ }^{\star}$ Elements appearing in italics are those with an empirical basis. Elements appearing in bold are those considered essential to give a system a Yes rating for the domain.

Adapted from ref. 44

Table 2. Items utilized for assessment of quality of individual articles of diagnostic studies by QUADAS tool

Item

1. Was the spectrum of patients representative of the patients who will receive the test in practice?

2. Were selection criteria clearly described?

3. Is the reference standard likely to correctly classify the target condition?

4. Is the time period between reference standard and index test short enough to be reasonably sure that the target condition did not change between the two tests?

5. Did the whole sample or a random selection of the sample, receive verification using a reference standard of diagnosis?

6. Did patients receive the same reference standard regardless of the index test result?

7. Was the reference standard independent of the index test (i.e. the index test did not form past of the reference standard)?

8. Was the execution of the index test described in sufficient detail to permit replication of the test?

9. Was the execution of the reference standard described in sufficient detail to permit its replication?

10. Were the index test results interpreted without knowledge of the results of the reference standard?

11. Were the reference standard results interpreted without knowledge of the results of the index test?

12. Were the same clinical data available when test results were interpreted as would be available when the test is used in practice?

13. Were uninterpretable/intermediate test results reported?

14. Were withdrawals from the study explained?

Adapted from ref. 45 with chronic spinal pain.

\section{MetHOdS}

\section{Inclusion Criteria}

\section{Types of Studies}

Clinical studies, in which, discography was part of the study design and analysis were included. Randomized clinical trials were given preference over cohort and observational studies in the grading. Since the key elements of discography are pain provocation and imaging of the IVD, we specifically searched for contingency tables or data that compared pain provocation to IVD imaging.

\section{Types of Participants}

Asymptomatic volunteers or symptomatic patients with chronic spinal pain were included. Patients may or may not have undergone prior surgery.

\section{Types of Interventions}

Discography, whether alone or in combination with other diagnostic tests, should be described clearly. At a minimum, pain provocation should be reported as no pain, dissimilar pain, or familiar/ exact pain. Disc architecture should be reported in terms of disc morphology. Postdiscography image validation with CT scanning or MR imaging was not mandatory $(20,41)$. The assessment of pain provocation and disc architecture should occur simultaneously. Non-ionic, watersoluble contrast media should be used. Ionic or oil-based dyes are hazardous, irritate discs, and are no longer in routine use (42).

\section{Exclusion Criteria}

\section{Types of studies}

Non-clinical studies, technical papers, expert opinion, review articles, and single case reports were excluded. Also excluded were clinical studies that used discography to select patients for treatment, but did not analyze the discography data separately.

\section{Types of interventions}

If discography was not practiced in accordance with modern principles, the study was excluded $(18,19,43)$ : (1) the absence of ethical barriers, i.e., discography performed on unwilling or vulnerable participants; (2) the absence of real time pain/architecture assessment - serial radiographs used instead of fluoroscopy; (3) the absence of systematic data re- 
Table 3. Designation of levels of evidence

\begin{tabular}{|l|l|}
\hline Level I & $\begin{array}{l}\text { Conclusive: Research-based evidence with multiple relevant and high- } \\
\text { quality scientific studies or consistent reviews of meta-analyses. }\end{array}$ \\
\hline Level II & $\begin{array}{l}\text { Strong: Research-based evidence from at least one properly designed } \\
\text { randomized, controlled trial; or research-based evidence from multiple } \\
\text { properly designed studies of smaller size; or multiple low quality trials. }\end{array}$ \\
\hline Level III & $\begin{array}{l}\text { Moderate: a) Evidence obtained from well-designed pseudorandomized } \\
\text { controlled trials (alternate allocation or some other method); b) } \\
\text { evidence obtained from comparative studies with concurrent controls } \\
\text { and allocation not randomized (cohort studies, case-controlled studies, } \\
\text { or interrupted time series with a control group); c) evidence obtained } \\
\text { from comparative studies with historical control, two or more single-arm } \\
\text { studies, or interrupted time series without a parallel control group. }\end{array}$ \\
\hline Level IV & $\begin{array}{l}\text { Limited: Evidence from well-designed nonexperimental studies from } \\
\text { more than one center or research group; or conflicting evidence with } \\
\text { inconsistent findings in multiple trials. }\end{array}$ \\
\hline Indeterminate: Opinions of respected authorities, based on clinical \\
evidence, descriptive studies, or reports of expert committees.
\end{tabular}

porting - results cannot be analyzed by reader; (4) the assessment of pain provocation alone or morphology alone; and (5) the use of oil based or ionic, high-osmolar, water soluble dyes as these agents can be hazardous when used for spinal procedures.

\section{Types of patients}

Patients with chronic spinal pain due to a disc protrusion or verifiable non-discogenic etiology were excluded. These exclusions include, but are not limited to, spinal stenosis, radiculopathy, traumatically or atraumatically induced fracture, instability, malignancy, myelopathy, infection, or systemic illness.

\section{Search Strategy}

Relevant clinical trials meeting the inclusion criteria for this review were identified in the following manner:

1. A computerized database search was performed of PUBMED (1940s-December 31, 2004), CINAHL - Cumulative Index to Nursing \& Allied Health Literature, EMBASE, and EBM - Evidence Based Medicine Reviews (Cochrane Database and Cochrane Central Register of Controlled Trials). The following terms were used in the search: dis- cogram, discography, intervertebral disc/diagnosis, intervertebral disc/ injection, and intervertebral disc/ pain. Boolean operators (AND/OR) and Boolean logic were used to optimize the search. Mesh headings were also used. A second iteration using the Mesh terms was used: Intervertebral Disk Displacement/radiography, Intervertebral Disk Displacement/ surgery, Injections, Spinal, and Sensitivity and Specificity, at the exclusion of the previous search strategy and at the exclusion of the terms, intrathecal and epidural. Limits (Adults, Human) were applied.

2. A review of the reference sections of selected articles was performed to identify other relevant studies.

3. Only English language articles were reviewed

\section{Method of Review}

From the computerized database search, individual citations, containing the author, title, keywords, and abstract, were printed. Citations were reviewed for exclusion criteria and if none were found, the journal article was obtained. Three physicians reviewed these articles. The articles were then tabulated based on: (1) the methodological quality; (2) the study design; (3) the number of patients; (4) the discography technique; (5) the pain assessment; (6) the use of a control disc; (7) the use of an advanced imaging tool, post-discography; (8) the use of discography as the criterion standard to study another imaging tool; (9) the presence of contingency tables or data to assess sensitivity and specificity of the pain response for IVD morphology; and (10) the conclusions.

\section{Methodological Quality}

The quality of each individual article was evaluated by the AHRQ (Table 1) and QUADAS (Table 2) rating scales (44-47). The AHRQ (5 points) and the QUADAS (14 points) are diagnostic study scoring instruments - their parameters are shown in Tables 1 and 2. We assigned pain provocation to be the index test and IVD imaging to be the gold standard. As described earlier, the validity of discography as an imaging tool has been investigated. The imaging information is important since treating an anatomically normal disc, irrespective of its ability to cause pain, seems unethical $(7,47)$. The validity of discography as a pain assessment tool remains unanswered.

Studies were then scored according to the AHRQ and QUADAS rating instruments, with the foregoing assumptions in mind. For inclusion, the studies had to meet at least $50 \%$ of the points for each scale (i.e., three of five for the AHRQ or seven of 14 for the QUADAS); studies were excluded if their scores were two of five for the AHRQ and six of 14 for the QUADAS.

\section{Strength of Evidence}

The level of evidence was evaluated as shown in Table 3.

\section{RESULTS}

\section{Literature Search}

The database search yielded 3,036 articles. Based on title alone, 2,439 could be excluded -607 abstracts were further reviewed. Of these, 431 were not relevant to the study question. One hundred and seventy-six full text journal articles were requested and reviewed. Ninety-four articles failed to meet the inclusion criteria. Eightytwo articles met the inclusion criteria, but after scoring with the AHRQ and QUADAS rating instruments, 11 (7, 8, 48-55) were excluded and 71 qualified (Fig. 1). 


\section{Methodological Quality}

There was one prospective, randomized, and controlled study. There were two randomized and prospective studies. There were seven prospective, controlled studies. There was one prospective, blinded study. There were 32 prospective studies. There were 27 retrospective studies. There was one paper that was both retrospective and prospective. There were no double blinded, randomized controlled studies. There were nine papers pertaining to cervical discography, two pertaining to thoracic discography, and 60 pertaining to lumbar discography. Additional data are tabulated in Table 4.

The findings of the 71 selected articles $(6,13,16,17,20-22,27,28,42,47,56$ $85,87-102,104,105,107-118)$ are summarized below.

In patients with negative post-myelography CT scans, Abdelwahab and Gould (13) reported that lumbar discographic imaging was normal; only two patients reported discordant pain, but otherwise the intradiscal injections were painless.

Annitta-Poika et al (6) reported that exact reproduction of pain was more like- ed Minnesota Multiphasic Personality Inly in ruptured or fissured discs and less ventory (MMPI) hysteria, hypochondrialikely in degenerative discs; based on the sis, and depression scores, may over report Adam's classification, the sensitivity and pain. In particular, patients that reported specificity of IVD morphology was $81 \%$ pain in a non-disrupted disc were more and $64 \%$ respectively for pain. CT scan- likely to test high on these MMPI scales.

ning post-discography provided minimal Bogduk and Aprill (57) reported additional information.

that the prevalence of concomitant cervi-

Aprill and Bogduk (56) reported that cal discogenic and cervical facet pain was a high intensity zone correlates signifi- $41 \%$ in patients with post-traumatic neck cantly with the presence of a high grade pain. Cervical discogenic pain alone was annular disruption - a radial tear that ex- prevalent in $20 \%$, and cervical zygapophtends to the outer annulus and circumfer- yseal joint pain alone was prevalent in entially spreads - and with concordant $23 \%$. The pain was neither discogenic nor pain provocation. The positive predictive facetogenic in $17 \%$. Cervical discography value of a high intensity zone for internal and cervical facet blocks together should disc disruption is $86 \%$.

Bernard (17) prospectively studied patients undergoing lumbar discography followed by CT. In $93 \%$ of patients, new information was obtained over prior CT or MR imaging and patient management was altered. The author supports the diagnostic utility of lumbar discography.

Block et al (22) determined that dis- painful disc is $23.3 \%, 96.8 \%, 91.3 \%$, and cographic pain reports are related to an- $46.5 \%$, respectively.

atomic abnormalities, but are also influenced by personality. Patients with elevat-

Carragee et al (59) performed a prospective controlled study on patients without low back pain who had undergone lumbar discography. They found that patients, with significant emotional and chronic pain problems, report significant back pain for at least one year after injection. Patients with outstanding disability claims account for more than $80 \%$ of those with persistent pain following discography. Patients with normal psychometric test results had no reports of significant long-term back pain following discography.

Carragee et al (60) performed a prospective controlled, longitudinal study on 50 subjects without low back pain who had undergone lumbar discography. A painful disc injection, independent of psychological profile, did not predict low back pain at the four-year follow-up. In this asymptomatic group, annular fissures, via discography and high intensity zones (HIZ), via MR imaging, were only weakly associated with a cumulative incidence of low back pain. Future back pain correlated with abnormal psychometric profiles, medication usage, chronic neck pain, and work loss.

In a prospective, controlled study, Carragee et al (61) performed lumbar discography in patients with mild persistent low back pain. In the group with mild back pain, $36 \%$ had significant, con- 
cordant pain reproduced during discography; in contrast, $73 \%$ of the patients with chronic low back pain had at least one positive disc injection. Since mild low back pain is "clinically insignificant", a positive disc injection in these patients should be false positive. Based on prevalence estimates of mild low back pain and chronic low back pain in an unselected back pain population, Carragee estimated the specificity of discography to be $74 \%$ and the positive predictive value to be $31 \%$. Even if a strict, low-pressure criterion is applied, the rate of positive discography in the mild low back pain group was $28 \%$ versus $27 \%$ in the chronic low back pain group. If patients with chronic low back pain are assumed to have had earlier episodes of mild low back pain, then there is a $30 \%-50 \%$ chance of having a positive concordant discogram prior to the development of serious low back pain illness. This implies that chronic low back pain illness may have nothing to do with a discogenic process, per se.

Carragee et al (62) performed discography in patients with and without low back pain following laminotomy/ discectomy. In this prospective observational study, a high percentage $(40 \%)$ of asymptomatic patients with normal psychometric testing reported significant pain on injection. Symptomatic patients had a rate of $63 \%$, but this higher rate may have been partly related to psychological and chronic pain issues.

Carragee et al (63) performed discography in eight patients without a history of low back pain, all of whom underwent iliac crest harvesting for non lumbar procedures. In this prospective study, 50\% of the volunteers reported usual and ordinary pain from their iliac crest harvest sites; the paper raised doubts about a patient's ability to differentiate spinal from non-spinal pain. Notably, the presence of an annular disruption predicted concordant pain reproduction. There are two caveats about this paper: (1) incisions can induce central facilitation/dorsal horn activation/secondary hyperalgesia (64); and (2) posterior iliac crest harvest sites, along with lower lumbar discs, will send afferent input to the upper lumbar and lower thoracic dorsal root ganglia (34, 35, 65). Albeit speculative, discography may experimentally induce pain that is referred to the iliac crest harvest site and hence, affect a patient's ability to differentiate between spinal and non-spinal pain.
Carragee et al (66) prospectively performed lumbar discography on 26 individuals, who had no history of low back pain. In the asymptomatic, chronic cervical pain, and somatoform disorder groups, positive disc injections occurred in $10 \%, 40 \%$, and $83 \%$ of patients, respectively. The false-positive rate of discography may be reduced if selected patients have normal psychometric profiles and do not have chronic pain. Annular disruption was associated with pain provocation. Curiously, control levels could be obtained in all patients and radiologically normal discs were typically painless. Specifically, patients with somatoform disorder could discriminate between painful and non-painful discs and could tolerate the procedure without sedation.

Carragee et al (67) performed a prospective, observational study of patients with and without low back pain to investigate the relevance of the high intensity zone to discographic pain provocation. The HIZ prevalence in the asymptomatic group was $24 \%$ and in the symptomatic group, $59 \%$. In the asymptomatic group, $69.2 \%$ of the discs with a HIZ were painful, compared to $10 \%$ without a HIZ. In the symptomatic group $72.7 \%$ of the discs with a HIZ were painful, compared to $38.2 \%$ of the discs without a HIZ. The authors concluded that the prevalence of the HIZ, in asymptomatic patients, is too high for the HIZ to be a reliable marker of symptomatic internal disc disruption.

Over a three-year period, Cohen et al (68) conducted a retrospective review of patients with chronic low back pain. The prevalence of discogenic pain in this population was $65 \%$, irrespective of whether the patients had prior back surgery. Needle insertion site does not affect the percentage of positive discogram results.

Colhoun et al (69) determined that lumbar discography has a sensitivity of $90.3 \%$ and a false-negative rate of $9.7 \%$, when surgical outcomes are used as the criterion standard. Pain provocation was most common with posterior annular tears. Outcome was $89 \%$ in those patients selected by provocative discography, compared to those $52 \%$ for those selected by noninvasive imaging.

Collins et al (70) determined that the correlation between MR imaging and discography in the evaluation of lumbar DDD was $89.5 \%$. No specific features on MRI, except annular bulging, could prognosticate outcomes following posterior spinal fusion. In patients selected by discography, nine of 12 patients improved with surgery.

Connor and Daren (71) concluded that cervical discography did not provide sufficient clinical utility to justify the potential risks and complications. In their retrospective review of 31 patients, 26 patients had concordant symptoms. Of these, 10 had excellent/good outcomes and 12 had fair/poor results.

Derby et al (72) concluded that patients with "chemically sensitized" discs had significantly better outcomes following interbody/combined fusion versus posterolateral fusions. "Chemically sensitized" refers to those discs wherein the static pressure, above opening static pressure, provokes familiar pain at less than 15 pounds per square inch (psi). Based on earlier disco manometry data, the authors suggest that reproduction of concordant pain at these low pressures is unlikely to represent physiological loads. The authors speculated that these discs represent pathological discs that have undergone inflammatory sensitization of their annular nociceptors.

Donelson et al (73) determined that McKenzie pain centralization assessments may reliably differentiate discogenic from non-discogenic pain and competent from incompetent annuli. Repeated end-range assessments may provide more relevant information than non-invasive imaging tests in identifying patients with discogenic pain.

Gill and Blumenthal (47) demonstrated that only $50 \%$ of patients with discographically positive inner-annular tears, but normal MR imaging, improve after anterior lumbar interbody fusion. Seventy-five percent of patients with annular tears that extend to the periphery or epidural space demonstrate functional improvement. This raises doubts about treating concordantly painful, but morphologically normal discs.

Grubb and Kelly (42) concluded that cervical discography is a safe and valuable technique. Discography should be performed in patients with chronic neck pain prior to surgical intervention; all accessible discs must be investigated. More than half the patients in their series had concordant pain provocation at three or more levels. Given the prevalence of multilevel, painful discs, only $10 \%$ of the authors' patients underwent surgery following discography. The authors believed that 
Table 4. Characteristics of articles included in systematic review

\begin{tabular}{|c|c|c|c|c|c|c|c|c|c|c|}
\hline Study & $\begin{array}{l}\mathscr{g} \\
\text { 妾 }\end{array}$ & 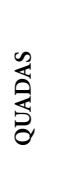 & 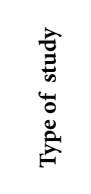 & 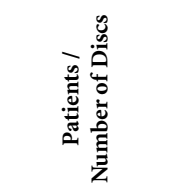 & 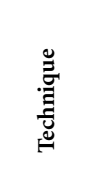 & 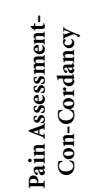 & & 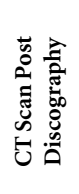 & 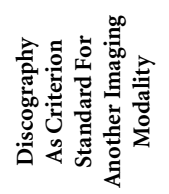 & 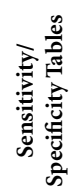 \\
\hline \multicolumn{11}{|l|}{ Cervical Spine } \\
\hline Grubb and Kelly (42) & $4 / 5$ & $9 / 14$ & $\mathrm{R}$ & 173 & RAO & Y & $\mathrm{Y}$ & $\mathrm{Y}$ & $\mathrm{N}$ & Y \\
\hline Bogduk and Aprill (57) & $4 / 5$ & $11 / 14$ & $\mathrm{R}$ & 56 & RAO & $\mathrm{Y}$ & $\mathrm{N}$ & $\mathrm{N}$ & $\mathrm{N}$ & $\mathrm{N}$ \\
\hline Connor and Darden (71) & $3 / 5$ & $10 / 14$ & $\mathrm{R}$ & 31 & RAO & $\mathrm{Y}$ & $\mathrm{U}$ & $\mathrm{N}$ & $\mathrm{N}$ & $\mathrm{N}$ \\
\hline Motimaya et al (85) & $3 / 5$ & $7 / 14$ & $\mathrm{R}$ & $16 / 46$ & LAO & $\mathrm{Y}$ & $\mathrm{U}$ & $\mathrm{N}$ & $\mathrm{N}$ & $\mathrm{N}$ \\
\hline $\begin{array}{l}\text { Parfenchuck and Janssen } \\
\text { (93) }\end{array}$ & $4 / 5$ & $11 / 14$ & $\mathrm{P}$ & 52 & UAO & $\mathrm{Y}$ & $\mathrm{U}$ & $\mathrm{Y}$ & $\mathrm{N}$ & $\mathrm{Y}$ \\
\hline Schellhas et al (100) & $3 / 5$ & $11 / 14$ & $\mathrm{P}$ & $10 \mathrm{Asx} / 10 \mathrm{Sx}$ & RAO & Y & $\mathrm{Y}$ & $\mathrm{Y} / \mathrm{N}$ & $\mathrm{N}$ & Y \\
\hline Schellhas et al (101) & $4 / 5$ & $11 / 14$ & $\mathrm{R}, \mathrm{P}$ & 40 & RAO & Y & $\mathrm{Y}$ & $\mathrm{N}$ & $\mathrm{N}$ & $\mathrm{N}$ \\
\hline $\begin{array}{l}\text { Siebenrock and Aebi } \\
\text { (106) }\end{array}$ & $4 / 5$ & $11 / 14$ & $\mathrm{R}$ & $27 / 39$ & $\mathrm{~L} / \mathrm{RAO}$ & $\mathrm{Y}$ & $\mathrm{N}$ & $\mathrm{N}$ & $\mathrm{N}$ & $\mathrm{N}$ \\
\hline Zheng et al (122) & $4 / 5$ & $11 / 14$ & $\mathrm{R}$ & $55 / 161$ & RAO & $\mathrm{Y}$ & $\mathrm{U}$ & $\mathrm{Y}$ & $\mathrm{Y}$ & $\mathrm{Y}$ \\
\hline \multicolumn{11}{|l|}{ Thoracic Spine } \\
\hline Wood et al (120) & $4 / 5$ & $11 / 14$ & $\mathrm{P}, \mathrm{CC}$ & $10 \mathrm{Asx} / 10 \mathrm{Sx}$ & $\mathrm{E}$ & $\mathrm{Y}$ & $\mathrm{Y}$ & $\mathrm{N}$ & $\mathrm{Y}$ & $\mathrm{Y}$ \\
\hline Schellhas et al (102) & $4 / 5$ & $11 / 14$ & $\mathrm{R}$ & 100 & E & Y & $\mathrm{Y}$ & $\mathrm{Y} / \mathrm{N}$ & $\mathrm{N}$ & $\mathrm{N}$ \\
\hline \multicolumn{11}{|l|}{ Lumbar Spine } \\
\hline Abdelwahab et al (13) & $3 / 5$ & $7 / 14$ & $\mathrm{R}$ & 15 & $\mathrm{E} / \mathrm{I}$ & Y & $\mathrm{N}$ & $\mathrm{N}$ & $\mathrm{Y}$ & $\mathrm{N}$ \\
\hline Antti-Poika et al (6) & $4 / 5$ & $11 / 14$ & $\mathrm{P}$ & 100 & $\mathrm{E}$ & $\mathrm{Y}$ & $\mathrm{U}$ & $\mathrm{Y}$ & $\mathrm{N}$ & $\mathrm{Y}$ \\
\hline Aprill and Bogduk (56) & $4 / 5$ & $11 / 14$ & $\mathrm{P}$ & 41 & $\mathrm{E}$ & Y & $\mathrm{Y}$ & $\mathrm{Y}$ & Y & Y \\
\hline Bernard (17) & $4 / 5$ & $11 / 14$ & $\mathrm{P}$ & 250 & $\mathrm{E}$ & $\mathrm{Y}$ & $\mathrm{N}$ & $\mathrm{Y}$ & $\mathrm{Y}$ & $\mathrm{N}$ \\
\hline Block et al (22) & $4 / 5$ & $11 / 14$ & $\mathrm{P}$ & 72 & $\mathrm{E}$ & Y & $\mathrm{Y}$ & Y & $\mathrm{Y}$ & Y \\
\hline Braithwaite et al (58) & $4 / 5$ & $11 / 14$ & $\mathrm{R}$ & 58 & $\mathrm{E}$ & Y & $\mathrm{Y}$ & Y & Y & Y \\
\hline Carragee et al (59) & $4 / 5$ & $12 / 14$ & $\mathrm{P} / \mathrm{C}$ & 26 Asx / 6 Sx & E & $\begin{array}{l}\text { N-inten- } \\
\text { sity only }\end{array}$ & $\mathrm{N}$ & $\mathrm{N}$ & $\mathrm{N}$ & $\mathrm{N}$ \\
\hline Carragee et al (60) & $5 / 5$ & $12 / 14$ & $\mathrm{P} / \mathrm{C}$ & $\begin{array}{c}46 \text { disco/ } \\
49 \text { no disco }\end{array}$ & $\mathrm{E}$ & $\begin{array}{l}\text { N-inten- } \\
\text { sity only }\end{array}$ & $\mathrm{N}$ & $\mathrm{N}$ & $\mathrm{N}$ & $\mathrm{N}$ \\
\hline Carragee et al (61) & $4 / 5$ & $11 / 14$ & $\mathrm{P} / \mathrm{C}$ & $\begin{array}{l}25 \text { mild LBP } \\
52 \text { severe LBP }\end{array}$ & $\mathrm{E}$ & Y & $\mathrm{Y}$ & $\mathrm{N}$ & $\mathrm{N}$ & Y \\
\hline Carragee et al (62) & $4 / 5$ & $11 / 14$ & $\begin{array}{l}\text { P/ RA, } \\
\text { C }\end{array}$ & $\begin{array}{l}20 \text { Asx -27 Sx- } \\
\text { discectomy }\end{array}$ & $\mathrm{E}$ & $\mathrm{Y}$ & $\mathrm{Y}$ & $\mathrm{N}$ & $\mathrm{N}$ & $\mathrm{Y}$ \\
\hline Carragee et al (63) & $3 / 5$ & $10 / 14$ & $\mathrm{P}$ & $\begin{array}{c}8 \text { Asx-iliac crest } \\
\text { harvest }\end{array}$ & E & Y & $\mathrm{N}$ & $\mathrm{N}$ & $\mathrm{N}$ & $\mathrm{Y}$ \\
\hline Carragee et al (66) & $3 / 5$ & $10 / 14$ & $\mathrm{P}$ & 26 Asx pts. & E & Y & $\mathrm{N}$ & $\mathrm{N}$ & $\mathrm{N}$ & $\mathrm{Y}$ \\
\hline Carragee et al (67) & $4 / 5$ & $11 / 14$ & $\mathrm{P} / \mathrm{C}$ & $42 \mathrm{Sx} ; 52 \mathrm{Asx}$ & $\mathrm{E}$ & $\mathrm{Y}$ & $\mathrm{Y}$ & $\begin{array}{l}\text { Y 31/ } \\
\text { N } 52\end{array}$ & $\mathrm{~N}$ & Y \\
\hline Cohen et al (68) & $4 / 5$ & $10 / 14$ & $\mathrm{R}$ & 127 & $\mathrm{E}$ & Y & $\mathrm{Y}$ & $\mathrm{N}$ & $\mathrm{N}$ & $\mathrm{N}$ \\
\hline Colhoun et al (69) & $3 / 5$ & $11 / 14$ & $\mathrm{R}$ & 195 & $\mathrm{E}$ & $\mathrm{Y}$ & $\mathrm{U}$ & $\mathrm{N}$ & $\mathrm{N}$ & $\mathrm{N}$ \\
\hline Collins et al (70) & $4 / 5$ & $11 / 14$ & $\mathrm{P}$ & 29 & $\mathrm{E}$ & $\mathrm{Y}$ & $\mathrm{U}$ & $\mathrm{N}$ & $\mathrm{Y}$ & $\mathrm{N}$ \\
\hline Derby et al (72) & $4 / 5$ & $11 / 14$ & $\mathrm{R}$ & 146 & $\mathrm{E}$ & Y & $\mathrm{U}$ & $\mathrm{U}$ & $\mathrm{N}$ & $\mathrm{N}$ \\
\hline Donelson et al (73) & $4 / 5$ & $11 / 14$ & $\mathrm{P}$ & 63 & E & $\mathrm{Y}$ & $\mathrm{Y}$ & $\mathrm{Y}$ & $\mathrm{Y}$ & $\mathrm{N}$ \\
\hline
\end{tabular}

$\mathrm{RA}=$ Randomized; $\mathrm{R}=$ retrospective; $\mathrm{P}=$ prospective $\mathrm{C}=$ controlled; $\mathrm{CC}=$ case controlled; $\mathrm{B}=$ blinded; $\mathrm{Y}=$ yes; $\mathrm{N}=\mathrm{No}$;

$\mathrm{E}=$ Extrapedicular; $\mathrm{I}=$ Interlaminar; $\mathrm{L}=$ Left; $\mathrm{U}=$ Unknown; $\mathrm{UAO}=$ Side unknown, anterior oblique; $\mathrm{RAO}=$ Right anterior oblique 
Table 4. Continued from previous page

\begin{tabular}{|c|c|c|c|c|c|c|c|c|c|c|}
\hline Study & 龸 & 离 & 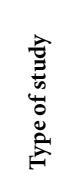 & 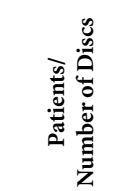 & 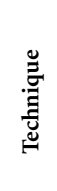 &  & 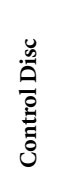 & 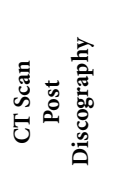 &  & 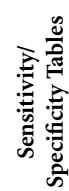 \\
\hline Gill and Blumenthal (47) & $3 / 5$ & $9 / 14$ & $\mathrm{R}$ & 53 & $\mathrm{U}$ & Y & $\mathrm{U}$ & $\mathrm{N}$ & $\mathrm{N}$ & $\mathrm{N}$ \\
\hline Greenspan et al (74) & $4 / 5$ & $11 / 14$ & $\mathrm{P}$ & $32 / 78$ & I & $\mathrm{Y}$ & $\mathrm{U}$ & $\mathrm{Y}$ & $\mathrm{N}$ & $\mathrm{Y}$ \\
\hline Heggeness et al (75) & $3 / 5$ & $8 / 14$ & $\mathrm{R}$ & $83 / 238$ & $\mathrm{U}$ & Y & $\mathrm{U}$ & $\mathrm{N}$ & $\mathrm{N}$ & $\mathrm{Y}$ \\
\hline Horton and Daftari (76) & $4 / 5$ & $11 / 14$ & $\mathrm{P}$ & $25 / 63$ & $\mathrm{E}$ & $\mathrm{Y}$ & $\mathrm{U}$ & $\mathrm{N}$ & $\mathrm{Y}$ & $\mathrm{N}$ \\
\hline Ito et al (77) & $5 / 5$ & $12 / 14$ & $\mathrm{P}$ & $39 / 101$ & $\mathrm{E}$ & Y & $\mathrm{U}$ & $\mathrm{Y}$ & $\mathrm{Y}$ & $\mathrm{Y}$ \\
\hline Lam et al (78) & $5 / 5$ & $11 / 14$ & P, B & 73 & $\mathrm{E}$ & Y & $\mathrm{U}$ & $\mathrm{N}$ & $\mathrm{Y}$ & Y \\
\hline Madan et al (79) & $3 / 5$ & $8 / 14$ & $\mathrm{P}, \mathrm{C}$ & 73 & $\mathrm{E}$ & Y & $\mathrm{U}$ & $\mathrm{N}$ & $\mathrm{N}$ & $\mathrm{N}$ \\
\hline Maezawa et al (80) & $4 / 5$ & $10 / 14$ & $\mathrm{R}$ & $523 / 1477$ & $\mathrm{E}$ & $\mathrm{Y}$ & $\mathrm{U}$ & $\mathrm{Y}$ & $\mathrm{N}$ & $\mathrm{Y}$ \\
\hline Manchikanti et al (81) & $3 / 5$ & $10 / 14$ & P, RA & 50 & $\mathrm{E}$ & $\mathrm{Y}$ & $\mathrm{U}$ & $\mathrm{N}$ & $\mathrm{N}$ & $\mathrm{N}$ \\
\hline Manchikanti et al (82) & $3 / 5$ & $8 / 14$ & P, RA & 120 & $\mathrm{E}$ & Y & $\mathrm{Y}$ & $\mathrm{N}$ & $\mathrm{N}$ & $\mathrm{N}$ \\
\hline McCutcheon et al (21) & $4 / 5$ & $11 / 14$ & $\mathrm{R}$ & 22 & $\mathrm{E} / \mathrm{I}$ & $\mathrm{Y}$ & $\mathrm{U}$ & $\mathrm{Y}$ & $\mathrm{Y}$ & $\mathrm{N}$ \\
\hline McFadden (83) & $4 / 5$ & $11 / 14$ & $\mathrm{P}$ & 200 & $\mathrm{E}$ & $\mathrm{Y}$ & $\mathrm{U}$ & $\mathrm{Y}$ & $\mathrm{N}$ & $\mathrm{N}$ \\
\hline Milette et al (16) & $4 / 5$ & $12 / 14$ & $\mathrm{R}$ & 58 & I & $\mathrm{Y}$ & $\mathrm{U}$ & $\mathrm{Y} / \mathrm{N}$ & $\mathrm{Y}$ & $\mathrm{Y}$ \\
\hline Milette et al (84) & $4 / 5$ & $11 / 14$ & $\mathrm{P}$ & 17 & I & $\mathrm{Y}$ & $\mathrm{U}$ & $\mathrm{N}$ & $\mathrm{N}$ & $\mathrm{N}$ \\
\hline Moneta et al (27) & $4 / 5$ & $9 / 14$ & $\mathrm{R}$ & $306 / 833$ & $\mathrm{E}$ & Y & $\mathrm{U}$ & $\mathrm{Y}$ & $\mathrm{Y}$ & $\mathrm{Y}$ \\
\hline Ohnmeiss et al (86) & $4 / 5$ & $11 / 14$ & $\mathrm{R}$ & $161 / 269$ & $\mathrm{E}$ & $\mathrm{Y}$ & $\mathrm{N}$ & $\mathrm{Y}$ & $\mathrm{N}$ & $\mathrm{N}$ \\
\hline Ohnmeiss et al (88) & $4 / 5$ & $11 / 14$ & $\mathrm{P}$ & 170 & $\mathrm{E}$ & $\mathrm{Y}$ & $\mathrm{U}$ & $\mathrm{Y}$ & $\mathrm{N}$ & $\mathrm{N}$ \\
\hline Ohnmeiss et al (89) & $4 / 5$ & $11 / 14$ & $\mathrm{P}$ & 187 & $\mathrm{E}$ & $\mathrm{Y}$ & $\mathrm{U}$ & $\mathrm{Y}$ & $\mathrm{N}$ & $\mathrm{Y}$ \\
\hline Ohnmeiss et al (90) & $4 / 5$ & $11 / 14$ & $\mathrm{P}$ & 187 & $\mathrm{E}$ & $\mathrm{Y}$ & $\mathrm{U}$ & $\mathrm{Y}$ & $\mathrm{N}$ & $\mathrm{Y}$ \\
\hline O'Neill et al (91) & $4 / 5$ & $11 / 14$ & $\mathrm{R}$ & $253 / 838$ & $\mathrm{E}$ & $\mathrm{Y}$ & $\mathrm{Y}$ & $\mathrm{N}$ & $\mathrm{N}$ & $\mathrm{N}$ \\
\hline Osti (92) & $4 / 5$ & $11 / 14$ & $\mathrm{P}$ & $33 / 114$ & $\mathrm{E}$ & $\mathrm{Y}$ & $\mathrm{U}$ & $\mathrm{N}$ & $\mathrm{Y}$ & $\mathrm{Y}$ \\
\hline Parker et al (94) & $1 / 5$ & $7 / 14$ & $\mathrm{P}$ & 23 & $\mathrm{E}$ & $\mathrm{Y}$ & $\mathrm{Y}$ & $\mathrm{N}$ & $\mathrm{Y}$ & $\mathrm{N}$ \\
\hline Ricketson et al (95) & $4 / 5$ & $11 / 14$ & $\mathrm{P}$ & 29 & $\mathrm{E}$ & Y & $\mathrm{U}$ & $\mathrm{Y}$ & $\mathrm{Y}$ & $\mathrm{Y}$ \\
\hline Sachs et al (20) & $4 / 5$ & $11 / 14$ & $\mathrm{P}$ & 59 & $\mathrm{E}$ & $\mathrm{Y}$ & $\mathrm{U}$ & $\mathrm{Y}$ & $\mathrm{N}$ & $\mathrm{Y}$ \\
\hline Saiffudin et al (96) & $4 / 5$ & $11 / 14$ & $\mathrm{R}$ & $58 / 152$ & $\mathrm{E}$ & Y & $\mathrm{U}$ & $\mathrm{N}$ & $\mathrm{Y}$ & $\mathrm{Y}$ \\
\hline Saiffudin et al (97) & $4 / 5$ & $11 / 14$ & $\mathrm{R}$ & $99 / 260$ & $\mathrm{E}$ & Y & $\mathrm{U}$ & $\mathrm{N}$ & $\mathrm{N}$ & $\mathrm{Y}$ \\
\hline Schechter et al (98) & $3 / 5$ & $8 / 14$ & $\mathrm{R}$ & $20 / 32$ & $\mathrm{U}$ & $\mathrm{Y}$ & $\mathrm{N}$ & $\mathrm{N}$ & $\mathrm{N}$ & $\mathrm{N}$ \\
\hline Schellhas et al (99) & $4 / 5$ & $11 / 14$ & $\mathrm{R}$ & 63 & $\mathrm{E} / \mathrm{I}$ & Y & $\mathrm{Y}$ & $\mathrm{Y} / \mathrm{N}$ & Y & $\mathrm{N}$ \\
\hline Schwarzer et al (103) & $4 / 5$ & $11 / 14$ & $\mathrm{P}$ & $92 / 255$ & $\mathrm{E}$ & Y & $\mathrm{Y}$ & $\mathrm{Y}$ & $\mathrm{N}$ & $\mathrm{Y}$ \\
\hline Schwarzer et al (104) & $4 / 5$ & $11 / 14$ & $\mathrm{P}$ & 92 & $\mathrm{E}$ & Y & $\mathrm{Y}$ & $\mathrm{Y}$ & $\mathrm{N}$ & $\mathrm{N}$ \\
\hline Simmons et al (110) & $4 / 5$ & $11 / 14$ & $\mathrm{P}$ & 164 & $\mathrm{E}$ & Y & $\mathrm{U}$ & $\mathrm{N}$ & $\mathrm{Y}$ & Y \\
\hline Smith et al (112) & $4 / 5$ & $11 / 14$ & $\mathrm{R}$ & 72 & $\mathrm{E}$ & $\mathrm{Y}$ & $\mathrm{U}$ & $\mathrm{Y}$ & $\mathrm{Y}$ & Y \\
\hline Smith et al (113) & $3 / 5$ & $11 / 14$ & $\mathrm{R}$ & 36 & $\mathrm{E}$ & Y & $\mathrm{U}$ & $\mathrm{N}$ & $\mathrm{N}$ & $\mathrm{N}$ \\
\hline Vanharanta et al (114) & $4 / 5$ & $11 / 14$ & $\mathrm{P}$ & $291 / 790$ & $\mathrm{E}$ & Y & $\mathrm{Y}$ & $\mathrm{Y}$ & $\mathrm{Y}$ & $\mathrm{Y}$ \\
\hline Vanharanta et al (28) & $4 / 5$ & $11 / 14$ & $\mathrm{P}$ & $91 / 290$ & $\mathrm{E}$ & Y & $\mathrm{Y}$ & $\mathrm{Y}$ & $\mathrm{Y}$ & $\mathrm{Y}$ \\
\hline Vanharanta et al (115) & $4 / 5$ & $11 / 14$ & $\mathrm{P}$ & 107 & $\mathrm{E}$ & Y & $\mathrm{Y}$ & Y & $\mathrm{Y}$ & Y \\
\hline Vanaharanta et al (116) & $4 / 5$ & $11 / 14$ & $\mathrm{P}$ & $300 / 816$ & $\mathrm{E}$ & Y & $\mathrm{Y}$ & Y & $\mathrm{Y}$ & Y \\
\hline Weishaupt et al (117) & $4 / 5$ & $11 / 14$ & $\mathrm{P}$ & $50 / 122$ & $\mathrm{E}$ & Y & $\mathrm{N}$ & $\mathrm{N}$ & Y & Y \\
\hline Walsh et al (118) & $5 / 5$ & $13 / 14$ & $\mathrm{P}$ & $10 \mathrm{Asx} / 7 \mathrm{Sx}$ & $\mathrm{E}$ & Y & $\mathrm{Y}$ & $\mathrm{N}$ & $\mathrm{N}$ & Y \\
\hline Wetzel et al (119) & $4 / 5$ & $11 / 14$ & $\mathrm{R}$ & 48 & $\mathrm{E}$ & $\mathrm{Y}$ & $\mathrm{N}$ & $\mathrm{N}$ & $\mathrm{N}$ & $\mathrm{Y}$ \\
\hline Yrjama et al (121) & $3 / 5$ & $8 / 14$ & $\mathrm{P}$ & 38 & $\mathrm{U}$ & $\mathrm{Y}$ & $\mathrm{Y}$ & $\mathrm{N}$ & $\mathrm{Y}$ & $\mathrm{Y}$ \\
\hline Zucherman et al (123) & $3 / 5$ & $9 / 14$ & $\mathrm{R}$ & 18 & $\mathrm{U}$ & Y & $\mathrm{Y}$ & $\mathrm{Y}$ & $\mathrm{Y}$ & $\mathrm{N}$ \\
\hline
\end{tabular}


investigating fewer levels on discography could lead to errors in surgical decisionmaking.

Greenspan et al (74) demonstrated that CT-discography was more successful than MRI in staging disc pathology. This implies that discography should be used as a confirmatory test, but not as a screening test. An MRI can be used as a screening test. Although this paper claimed to study patients with disc protrusions (HNP), careful review of their materials and methods sections suggested that these patients had chronic low back and leg pain. Furthermore, these patients were contemplating elective spine surgery and did not present with radiculopathy or radicular pain. Hence, we included this paper.

Heggeness et al (75) performed discography on patients who underwent laminectomy and partial discectomy. Seventy-two percent of operated discs were concordantly painful, as compared to $38 \%$ of non-operated discs. Thirty-four percent of the operated discs leaked dye posteriorly, as compared to $21 \%$ of the non-operated discs.

Horton and Daftari (76) concluded that the vast majority of relatively normal appearing discs on T2-weighted MRIs (white/bulged, white/flat) appear normal or do not provoke pain during discography: normal discs negatively correlate with discogenic pain. Conversely, single level abnormalities on MRI, such as a dark/torn disc, are useful in predicting discogenic pain. If the MRI demonstrates an intra-annular cleft, speckled and dark/ bulging discs, or multilevel disc abnormalities, then discography is indicated for diagnosis and surgical planning.

Ito et al (77) noted that radial tears are commonly found on MRI, but have a low correlation with concordant pain reproduction. Combined tears (posterior radial + concentric tears) represent the high intensity zone that is seen on lumbar spine MRIs. Discography is more accurate than MRIs in detecting outer annular disruptions. MR imaging identification of combined tears, severe disc dehydration, and severe disc narrowing/ massive disc degeneration are good predictors of concordant pain during discography. Moderate disc dehydration and loss of disc height are not good predictors of concordant pain.

Lam et al (78) demonstrated that HIZs have a sensitivity, specificity, and positive predictive value for pain provoca- tion of $81 \%, 79 \%$, and $87 \%$. The HIZ may represent painful internal disc disruption. Madan et al (79) concluded that patients selected for circumferential $\left(360^{\circ}\right)$ lumbar fusion by discography (Group B), did as well as those not undergoing discography (Group A). They concluded that provocative discography is not needed to select patients for spinal fusion. Careful examination of their paper reveals that a higher percentage of Group A patients $(65.8 \%)$, as compared to Group B (43.7\%), had high grade degenerative changes on MRI: sequestered herniations, intervertebral instability, listhesis, or $>50 \%$ loss of disc height. Additionally, in Group A there was an increased prevalence of Modic endplate changes as compared to Group B. Given the presence of this selection bias, the author's conclusions may be challenged.

Maezawa and Muro (80) demonstrated that pain provocation ratios were extremely low in patients with Dallas Discogram Description grade 0 annular degeneration. In patients with Grade 1, Grade 2, and Grade 3 annular degeneration, concordant pain was more likely than discordant pain to be reproduced during discography. The discrepancy between concordant pain ratios and discordant pain ratios tended to decrease, however, with Grade 3 annular degeneration. Grade 0 annular tears were not likely to be associated with pain, but Grade 3 annular tears were. The rate of discordant and concordant pain responses rose in relation to the annular tear grade. However, the rate of concordant pain responses outpaced discordant pain responses with progressive annular tear grade. Despite the author's conclusions that pain provocation ratios bear little relation to annular degeneration and annular tears, their reported data don't support their conclusions.

Manchikanti et al (81) demonstrated that provocative discography can produce similar results in patients with and without somatization disorder, with and without depression, and with and without generalized anxiety disorder. This implies that psychological factors do not impair a patient's ability to report pain during discography.

Using diagnostic spinal injections, Manchikanti et al (82) studied the relative contributions of various structures in the low back. Of those patients with truly negative and falsely positive facet joint pain, $43 \%$ reported concordant discogenic pain.

McCutcheon and Thompson (21) were the first to report CT scanning, post discography. Discography reproduced symptoms in $77 \%$ of patients with intractable low back pain for whom physical examination, EMGs, CTs, and metrizamide myelography were negative. The direction of intradiscal contrast dispersion corresponded to usual pain in $73 \%$ of patients. Outer annular tears were present in $82 \%$ of patients.

McFadden (83) reported rates of $100 \%$ and $46 \%$ respectively for back and leg pain reproduction in patients with chronic low back pain that underwent lumbar discography. Reproduction of leg pain was more likely to occur during discography in those patients experiencing $>50 \%$ of their average daily pain just prior to discography.

Millette et al (16) concluded that disc height loss, decreased central disc intensity, and the HIZ, on MR imaging, highly predict symptomatic outer annular tears. With respect to the degree of disc degeneration, extent of disruption, or the presence of discogenic pain, there was no significant difference between disc protrusions, disc bulges, and discs with normal contours, but abnormal signal. Hence, classifying disc pathology based on the Disc Extension Beyond the Interspace (DEBIT) model (i.e., normal, bulging, protruded, or extruded) is not useful for discogenic pain; this classification system does not provide significant discriminative information to the reader in terms of identifying discogenic pain.

Using strict inclusion criteria, Millette et al (84) identified 33 patients who had concordant reproduction of single level back and leg pain following discography. Intradiscal lidocaine was instilled, but was successful in only 17 patients. A $75 \%-100 \%$ reduction of leg pain (16 of 17) and back pain (13 of 17) occurred. Discography may reproduce leg pain, which is referred from the disc and not due to iatrogenic nerve injury.

Moneta et al (27) noted that only outer annular tears predicted similar or exact reproduction of a patient's pain. Grade 2 and 3 annular tears had an odds ratio of 51.2 and 126.8 for reproducing exact pain, as compared to no pain or “just pressure." Generalized disc degeneration was only able to predict dissimilar pain. Gender, age, and spinal level had no 
affect on these conclusions. These results agree with the data from Maezawa (80).

Motimaya et al (85) demonstrated that 14 of 16 patients who underwent discography had good or excellent results following anterior cervical discectomy and fusion. They concluded that cervical discography might help localize symptomatic levels in patients with intractable neck pain and indeterminate non-invasive imaging studies.

Ohnmeiss et al (86) demonstrated, during cervical discography, a significant relationship between IVD morphology and pain provocation. Among normal appearing discs, concordant pain was provoked in $14.3 \%$ and among abnormal discs, concordant pain was provoked in $77.8 \%$. Abnormal discs are those with disruption or disruption/extravasation. Painless, but abnormal appearing discs tended to be associated with older patients.

Pain drawings can be scored by a system developed by Ransford (87); these scores can predict how the majority of patients test on the hysteria and hypochondriasis scales of the Minnesota Multiphasic Personality Inventory (87). According to Ohnmeiss et al (88), there is good intra-rater reliability in using the Ransford system to score pain drawings as abnormal or normal. Ohnmeiss et al (88) demonstrated a relationship between pain drawings and lumbar CT-discography, in which a false positive discogram is defined as similar or exact pain provocation in a non-disrupted disc. The false-positive rate in patients with normal pain drawings is $12.3 \%$, compared to $50 \%$ for those with abnormal pain drawings. In patients with normal pain drawings, $6.4 \%$ report pain at all three levels and $24.8 \%$ at no level. In patients with abnormal pain drawings, $24.4 \%$ report pain at all three levels and $11.1 \%$ at no level. The specificity, sensitivity, and accuracy of pain drawings in identifying patients with false-positive pain reports during discography are $83.6 \%, 58.1 \%$, and $78.0 \%$. In contrast to Carragee's (63) paper, Ohnmeiss's paper supports the ability of patients during discography to recall and compare their baseline to provoked pain. In fact, patients in Ohnmeiss's group were, in effect, "blinded" to the etiology of their pain. Some patients had non-dermatomal pain drawings, but by their willingness to undergo discography, one can assume that these patients did not have insight into the physiology/etiology of discogenic pain.
In Carragee's (63) paper, patients experienced pain following iliac crest harvesting, and prior to discography knew the etiology of their pain.

Ohnmeiss et al $(89$,$) in a study simi-$ lar to their earlier study (87) further studied those patients with normal and abnormal pain drawings. Normal pain drawings were significantly related to painful, disrupted lumbar discs, particularly when a single disc level was involved. Surprisingly, $58.3 \%$ of patients with pain drawings confined to their low back and buttocks did not have disc pathology. If there was pain in the posterior, but not anterior thigh or leg, more than $75 \%$ of these patients had a positive L5-S1 disc. In patients with anterior thigh pain and with/ without posterior thigh/leg pain, the L45 disc was involved $(>63 \%)$. In patients with exclusively anterior leg pain, the L34 disc was primarily involved (71.4\%). In patients with abnormal pain drawings there was no relationship between disc pathology and pain location.

In Ohnmeiss et al (90), outer annular disc disruption that did not deform the outer annular wall was as frequently associated with lower extremity pain as were discs with severe disruption and outer annular wall deformation. This paper lends support to Milette's (16) argument that the DEBIT classification is clinically not very useful for lumbar discogenic pain. Patients with grade 2 disruptions were more likely to report aching pain than were patients with grade 3 disruptions. Since grade 2 and 3 disruptions both produce distal lower extremity pain, this report corroborates the findings of O'Neill (51): lower extremity pain may be referred from the disc, in the absence of frank neural compression. In patients presenting with lower extremity pain, $81.7 \%$ had symptomatic disc disruptions. In patients with pain radiating below the knee, $84.1 \%$ had symptomatic disc disruptions. In patients whose pain was confined to the low back or buttocks, $41.7 \%$ had symptomatic disc disruptions.

O'Neill and Kurgansky (91) used an analytical model to calculate the falsepositive rate of a painful lumbar disc during pressure controlled discography. Their data, from a group of symptomatic low back pain patients, were compared to an asymptomatic low back pain group, culled from Carragee et al (61-66). All positive discs from Carragee's groups were considered to be false-positive. Two hundred fifty-three patients had at least one concordantly painful disc and one pain free control. In all, there were 441 concordantly painful and morphologically abnormal discs. A histogram of number of discs versus distention pressures (pain thresholds) was generated. Fifty-one discs were painful upon the immediate delivery of contrast; these were classified as contact-sensitive discs, because they had distention pressure of zero. The remaining discs were classified as pressure-sensitive discs, with a distention pressure that was $\geq 1$. This group had a mean pain threshold of 19.8 psi with standard deviation of 15 psi. However, there were two peaks in the histogram, one at 8 psi and another at 30 psi. This suggested that the histogram could be a composite of two distributions: One group that was minimally sensitive to pressure; and another group that was moderately sensitive to pressure. The authors assumed minimally-sensitive discs to be false-positives. The disc frequency-distention pressure distributions, from the asymptomatic and minimallysensitive groups, could both be modeled with gamma distributions. Hence, the authors were able to estimate the false-positive rate at arbitrary distention pressure (pain threshold) cut-offs. At 50 psi, the false-positive rate was $100 \%$. At 25 psi, the false- positive rate was $50 \%$ and at $14 \mathrm{psi}$, the false-positive rate was $10 \%$. The falsepositive rate of discs with pain thresholds of less than 10 psi could not be calculated. For patients with pain thresholds less than $10 \mathrm{psi}$, the authors deferred to the practitioner's clinical judgment.

Osti and Fraser (92) demonstrated that discography was more accurate than MR imaging in detecting annular pathology. None of their discographically normal discs reproduced typical pain. Ninety-two percent of discs (36 of 39) with typical pain reproduction demonstrated outer annular tears.

Parfenchuck and Janssen (93) demonstrated that certain MRI patterns correlate with positive, equivocal, or negative cervical discography. There was no relationship between pain response and morphology as seen on discography or CT-discography. Leakage of contrast occurred in almost all discs irrespective of their ability to provoke pain.

Parker et al (94) investigated the outcome of posterolateral fusion in those patients selected by lumbar discography. Only $39 \%$ of patients had good outcomes 
at an average of 47 months. Patients on worker's compensation or on chronic disability tended to do poorly. Due to concerns about operative complications, the authors questioned the merits of interbody fusion, irrespective of discographic findings.

Ricketson et al (95) noted that HIZs are not necessarily associated with a concordant pain response during lumbar discography. HIZs, however, were not seen in morphologically normal discs. The authors noted a significant correlation between the grade of annular tear and a concordant pain response at the L3-4 and L4-5 levels, but not the L5-S1 levels. Review of their data, however, demonstrates that 11 of 14 patients, with grade 3 annular tears at L5-S1, had concordant pain reproduction. None of the discs with grade 0 annular tears had concordant pain responses.

Sachs et al (20) developed the Dallas Discogram Description for classifying low-back disorders, via CT-discography. The contrast-enhanced, axial view of the IVD was useful for imaging disc pathology. Of particular importance was the ability of CT-discography to distinguish between disc degeneration and annular disruption. The authors noted a correlation with disc degeneration severity and pain concordancy. A better correlation was demonstrated for annular disruption and pain concordancy.

Saiffudin et al (96), in contrast to Ricketson et al (95), noted that the HIZ is a marker of a painful annular tear. For diagnosing a concordantly painful, annular tear, the MRI sensitivity, specificity, positive predictive value, and negative predictive value, were $26.7 \%, 95.2 \%, 88.9 \%$, and $47 \%$, respectively. Notably, during discography 43 discs had normal morphology and all were pain free. These discographically normal discs were normal on MRI. Out of 80 with posterior annular tears, 70 had concordantly painful discograms.

Saiffudin et al (97) demonstrated that pain experienced in the buttock, hip, groin, or lower limb can arise from the posterior annulus of the intervertebral disc without direct involvement of the nerve root. There was a significant association between isolated posterior tears and the production of concordant pain in the back or legs. Isolated anterior annular tears were not associated with pain radiation. With regard to the reproduction of radiating pain, there was no sig- nificant difference between full and partial thickness tears. These results support those of Ohnmeiss et al (90) and Milette et al (16). There was no significant relationship between level of discography and extent of radiation of pain. These results differ somewhat from Ohnmeiss et al (90) but both authors concur that radiating leg pain can occur in the absence of a compressive disc lesion.

Schecter et al (98) retrospectively reviewed the outcomes of 25 patients with internal disc disruption, following single-level, posterior lumbar interbody fusion with autogenous, iliac crest bone grafts. Of these patients, 20 had pre-operative lumbar discography. Overall, $89 \%$ of the patients had an excellent or good outcome. These results are better than the results of Parker et al (94) wherein the intervertebral disc was not excised or fused.

Schellhas et al (99) performed lumbar discography in 63 patients, with a total of $100 \mathrm{HIZ}$ discs on MRI. Eighty-seven of these proved to be concordantly painful. In these 63 patients, 67 control discs were studied. Sixty-five of the 67 discs were non-concordantly painful. In patients with symptomatic low back pain, the HIZ was shown to be a reliable marker of outer annular disruption.

Schellhas et al (100) performed fourlevel cervical discography on 10 asymptomatic volunteers and 10 patients with chronic neck/head pain. Based on MRI, 20 discs were morphologically normal and 20 were abnormal in the asymptomatic group. Based on discography, five were normal and 35 discs were abnormal in this asymptomatic group. Out of these 35 discs, 17 demonstrated extraanular leakage. None of the discs were intensely painful: the average pain intensity was 2.42 out of 10 . By definition, all painful discs were discordant. In the symptomatic group, based on MRI, 11 discs were normal and 29 were abnormal. In this group, only one disc was discographically normal. The intensity of provoked pain per disc level was high; the average pain intensity was 5.2 out of 10 . Often, due to provoked pain, the injection had to be terminated earlier than anticipated. Ten out of the 11 MRI normal discs demonstrated annular tears, of which two were painful. Overall, discographically normal cervical discs are painless and intensely painful discs have tears in the inner and outer annulus.

Schellhas et al (101) performed upper cervical discography, C2-3, C3-4, and
C4-5, on 40 patients with head/neck pain. Eighteen of these patients had reproduction of concordant craniovertebral pain during C2-3 injection, nine patients reported neck pain, 19 patients reported head pain, and four patients reported shoulder pain. Pre-procedure MRIs demonstrated normal or mildly degenerative discs. All patients had fissuring of the $\mathrm{C} 2$ 3 disc. The authors demonstrated concordant pain responses, particularly headache, following C2-3 discography. Pain reproduction at $\mathrm{C} 2-3$, however, does not correspond to $\mathrm{C} 2-3$ discographic or MR morphology. Similar, but lesser, findings were noted at C3-4. Almost all the patients with C2-3 pain had multilevel symptomatic cervical disc disease and these patients were not deemed to be appropriate surgical candidates. Paradoxically, the authors noted that the majority of patients did well with upper cervical medial branch radiofrequency thermocoagulation. This raises an interesting question: Should single level C2-3 provocative discography be used to exclude surgical candidates, rather than performing C3-7 cervical discography to select patients for surgery (42)? Similarly, this study raises doubts about cervical discs as isolated pain generators, such as: If a patient has concordant discogenic pain, but does well with therapies targeting a different pain generator (upper cervical medial branches), then an anatomical/structural model of cervical discogenic pain must be challenged.

Schellhas et al (102) concluded that thoracic discography could be performed safely. They performed thoracic discography on 100 patients at one to eight levels. The results were presented in descriptive fashion. Pain was typically reproduced in the posterior thoracic spine. Extraspinal pain in the chest and abdomen was also reproduced, but not in isolation. The location of the annular tears correlated with the location and type of pain. Overall, the authors noted that vertebral endplate abnormalities were painful approximately $75 \%$ of the time. Pain concordancy, however, was poor at $50 \%$.

Schwarzer et al (103) performed lumbar discography and lumbar facet/ lumbar medial branch blocks on 92 consecutive patients with chronic low back pain. Forty-five patients (49\%) had neither discogenic nor zygapophyseal joint pain; 33 patients $(39 \%)$ only had lumbar discogenic pain; five patients $(6 \%)$ had exclusively zygapophyseal joint pain; 
three patients (3\%) had both zygapophyseal and discogenic pain; and six patients were excluded from the analysis because they did not undergo confirmatory $\mathrm{z}$ joint blocks or discography. In this population, discogenic pain was more common than zygapophyseal joint pain, and both were unlikely to co-exist. The authors challenged the concept that interrelated degenerative processes involving the three-joint complex produce symptoms at all three joints.

Schwarzer et al (104) determined that the rate of internal disc disruption in a prospective group of chronic low back pain was $39 \%$. Apparently, the patients in this paper are identical to previously reported patients (103) and the prevalence of discogenic pain was already reported (103). The unique features of this paper were that the findings on history and physical exam bore no relationship to the presence or absence of discogenic pain. These findings included referral of pain to the leg. This paper did not evaluate the McKenzie Assessment, which was shown to correlate with lumbar discogenic pain (73).

Siebenrock and Aebi (106) reported $73 \%$ successful outcomes with a good to excellent result in patients who underwent one or two level anterior cervical discectomy and fusion following cervical discography. They reported better outcomes than the 35 to $46 \%$ rates reported in the literature $(107,108,109)$. Hence, the authors considered cervical discography to be valuable for patient selection.

Simmons et al (110) demonstrated that lumbar discography and MR imaging agreed in 55\% of cases and disagreed in $45 \%$. Similarly, at the disc level there was agreement in $80 \%$ of cases and disagreement in $20 \%$. Seventy-six percent of the discs considered to be abnormal by both imaging techniques, were symptomatic. In those discs that were morphologically abnormal by MRI, but normal by discography, $100 \%$ were asymptomatic. In those discs that were morphologically normal by MRI, but abnormal by discography, $62 \%$ were symptomatic. MRI alone should not be used to diagnose symptomatic internal disc disruption. One caveat of this study was that abnormality was defined as either loss of intradiscal signal or annular bulging. As stated in Ohnmeiss et al (90) and Millette et al (16), annular bulging is not predictive of discogenic pain. Simmon's paper was published before introduction of the high intensity zone (56) and did not mention endplate abnormalities (111).

Smith et al (112) demonstrated a fair to good interobserver reliability for detecting HIZs. The sensitivity of the HIZ for detecting high-grade, symptomatic annular tears was poor at $31 \%$. The specificity of the HIZ in detecting high-grade, symptomatic annular tears was high at $90 \%$. Overall, the positive predictive value of the HIZ for detecting high-grade, symptomatic annular tears was only $40 \%$. In patients with a grade 0 to 1 annular disruption, $88 \%$ had no pain provocation. Of those patients with grade 4 annular disruptions, 36\% had exact pain reproduction and $59 \%$ had no pain. Thus, the vast majority of patients with exact pain reproduction had discographic evidence of abnormal morphology. Conversely, the majority of patients with discographic evidence of abnormal morphology do not have exact pain reproduction.

Smith et al (113) demonstrated that $68 \%$ of patients with lumbar discogenic pain had improved at a mean followup of 4.9 years. Favorable indicators were pain onset at an older age, shorter duration of symptoms, and the absence of psychiatric disease.

Vanharanta et al (114) demonstrated that normal discs are typically painless and degenerated discs are painful; however, severely degenerated discs that are painless often occur with advancing age. Degenerative processes are associated with aging and are poorly correlated with symptomatic low back pain. Annular disruption scores are significantly lower in painless discs, as compared to painful discs.

Vanharanta et al (28) demonstrated that annular tears develop prior to disc degeneration and are more likely to be the source of pain. Patients reporting pressure, as compared to those reporting pain, are more likely to have lower degeneration and annular disruption scores. In patient groups with different types of pain (exact, similar, dissimilar), the degeneration and annular disruption scores were about the same. However, in young males and females with concordant pain, the annular disruption scores were higher than the degeneration scores.

Vanharanta et al (115) noted that measuring IVD height is a poor method to detect early, painful disc deterioration, but does correlate with disc degeneration.
Discs demonstrating slight degeneration are often painful, but detecting this narrowing occurs only with moderate to severe degeneration.

Vanaharanta et al (116) demonstrated that CT/discography is useful when a clinical diagnosis cannot be confirmed by conventional imaging. In their series, referred patients carried diagnoses such as HNP, DDD, lumbar syndrome, or lumbar radiculopathy; however, the authors considered these to be non-specific low back pain. Intradiscal deterioration and exact/ similar reproduction of pain played a role in $86 \%, 80 \%, 56 \%$, and $59 \%$, of those patients with HNP, DDD, lumbar syndrome, and lumbar radiculopathy. Even with a high index of clinical suspicion, $\mathrm{CT} /$ discography is useful for precision diagnosis.

Weishaupt et al (117) demonstrated that normal discs on MRI are generally not painful and have a negative predictive value of $98 \%$. Disc degeneration and HIZs have a $59 \%$ and $56 \%$ positive predictive value for symptomatic internal disc disruption; these results are similar to Smith (112). Modic type 1 and type 2 (106) endplate changes correlate with concordant pain provocation. In contrast to the conclusions of Saiffudin et al (97) and Aprill and Bogduk (56), but in agreement with the conclusions of Ricketson et al (95) and Carragee et al (67), Weishaupt did not believe the HIZ is a reliable marker of symptomatic internal disc disruption.

Walsh et al (118) performed lumbar discography on 10 asymptomatic volunteers and seven symptomatic patients with low back pain. In the assessment of pain intensity, pain related behaviors, and pain concordancy, the interrater reliability was high at $0.99,0.93$, and 0.88 , respectively. In the asymptomatic group, if a positive disc was defined as a disc that reproduced significant pain, then the falsepositive rate was 0 . In the asymptomatic group, five of the 30 discs reproduced pain of low-level intensity. Six of the seven symptomatic patients had positive discograms, based on the study criteria: abnormal disc morphology and reproduction of typical pain. In the symptomatic group, seven discs out of 20 tested were positive (35\%). The percentage of abnormal discographic morphology in the asymptomatic group was $17 \%$, versus $65 \%$ in the symptomatic group. Lumbar discography is a specific diagnostic test.

Wetzel et al (119) retrospectively 
studied 48 patients with low back pain, 11 of which had prior surgery. All patients underwent lumbar discography at 1-3 levels, but not at the previously operated levels. All patients underwent a lumbar arthrodesis to include all discographically symptomatic levels. A variety of different types of surgical techniques were used and some patients required multiple revisions. Overall, $46 \%$ of patients had satisfactory outcomes at a mean of 35.2 months. Outcomes strongly correlated with solid arthrodesis. Negative correlates included smoking and prior surgery.

Wood et al (120) demonstrated that Schmorl's nodes in thoracic discs may be intensely painful. In asymptomatic patients, however, this pain is non-concordant. They performed four-level thoracic discography on 10 asymptomatic volunteers and multilevel thoracic discography on 10 patients with chronic thoracic pain. In asymptomatic patients, the average pain response per disc level was 2.4 out of 10 . However, only three out of 40 discs in this group were intensely painful and these three discs had Schmorl's nodes. The remaining 37 of 40 discs just demonstrated pressure or no pain; thoracic discography is not painful in the truly asymptomatic patient. In the symptomatic patients, 24 of 48 discs were concordantly painful, 17 of 48 discs were discordant, and seven discs were painless. The concordantly painful discs registered pain intensities averaging 8.5 of 10 . The discordantly painful discs registered pain intensities averaging 4.8 of 10 . A number of morphologically abnormal discs via discography were read as normal on MR imaging. There was a general trend toward more painful responses in patients with greater degrees of pathology, particularly in those with Scheuermann's disease. In the symptomatic group, $55 \%$ of the discs reproduced concordant pain, which raises doubts about surgical treatments for thoracic pain.

Yrjama et al (121) studied a group of patients with low back pain using bony vibration, ultrasound, and discography. The authors concluded that, prior to discography, the combination of bony vibration and ultrasound might be useful as a screening test.

As compared to cervical discography, Zheng et al (122) demonstrated that MR imaging has a $51 \%$ false-negative and a $27 \%$ false-positive rate in identifying symptomatic disc patients for fusion.
They suggested that there is a high chance that a hypointense signal and small disc protrusions are pain generators, but this is not always true. Discography may spare unnecessary levels from being fused.

Zucherman et al (123) identified concordantly painful annular tears in discs that were normal by MR criteria. The authors commented that the interpretation of normality in MR imaging is subjective and may miss other markers of internal disc disruption, such as a high intensity zone. This paper underscores the importance of having the discographer view MR images personally.

\section{Strength of Evidence}

Based on the review of all the available studies, there is strong evidence for discography as an imaging tool for provocation of pain with intradiscal distension, and in identification of patients with chronic lumbar discogenic pain. The evidence was moderate in identification of patients with chronic cervical discogenic pain, whereas it was limited in chronic thoracic discogenic pain.

\section{Discussion}

This systematic evaluation showed strong evidence for the utility of discography as an IVD imaging tool. There is strong evidence that intradiscal distention can produce pain. There is strong evidence supporting the role of discography in identifying patients with chronic lumbar discogenic pain. There is moderate evidence supporting the role of discography in identifying patients with chronic cervical discogenic pain. There is limited evidence supporting the role of discography in identifying patients with chronic thoracic discogenic pain.

\section{Methodological Criteria}

Deeks (124) provided a framework to evaluate a diagnostic study's quality and likelihood of bias. Unlike the AHRQ (44) or the QUADAS (45), this involved looking at only three criteria: 1) patient sample, 2) reference standard, and 3) index test. Deeks (124) recommended optimal patient recruitment, optimal execution of the index test, and optimal execution of the reference standard. The majority of the papers met two of these criteria, but only a few met three. All papers met at least $50 \%$ of the AHRQ or QUADAS criteria $(44,45)$.

Knottnerus et al (125) stated that there are several methodological challenges that must be addressed in diagnostic accuracy studies. These include the "gold standard' problem, spectrum and selection bias, "soft" measures (subjective phenomena), observer variability and bias, complex relations, clinical impact, sample size, and the rapid progress of knowledge (125). In this systematic review, we address these concerns, but unfortunately, most discography studies cannot overcome these methodological limitations.

There is no "gold standard" for discogenic pain and thus, we considered pathological disc morphology to be the "gold standard". The majority of the selected studies were able to describe, in detail, the index test (assessment of pain) and reference or "gold standard" test (assessment of disc morphology). All the studies suffered from selection bias and a few from spectrum bias. The assessment of pain is a soft measure and a few papers challenged the ability of patient's to consistently report pain during discography. Observer variability and observer bias were present in all papers and only a few attempted to minimize these factors. These few studies attempted blinding, in which, independent observers reviewed either the patient's videotape or the discographic images. Inter-observer and intraobserver validation of discographic imaging was performed in only a few studies. Inter-observer validation of pain response was performed in only a few studies; since pain is a subjective experience, the utility of this latter validation scheme is questionable. Complex relations were not accounted for in all studies, since discography is no longer performed as an isolated test. Discography is performed on patients with persistent spinal pain, after a number of other tests have been ordered. Sample sizes for most studies were small. In terms of patient selection, methodology was poor for most papers and all papers could be criticized for selection bias. Nonetheless, ethical barriers prevent performing invasive tests on large patient samples that may or may not have disease. This is why most discography studies were retrospective or prospective, but not randomized and double blinded. A number of studies presented data in 2 by 2 contingency table format. This format is useful to readers and could be used to compare study results. Since, discography results were presented as only positive or negative, receiver operator characteris- 
tic curves could not be generated. Finally, the rapid progress in our understanding of pain and pain processing may impact the diagnostic accuracy of discography.

\section{Historical Context}

In the early 1900s, the HNP was thought to be the most common etiology of low back pain $(126,127)$. Unfortunately, the diagnosis could not be made without the use of oil-based myelograms or exploratory surgery, both of which were hazardous $(117,132)$. A safer diagnostic tool was required to identify symptomatic intervertebral disc disorders. Discography was introduced in the 1950s (1-5) as a diagnostic imaging tool, but failed to gain widespread acceptance due to concerns about damaging the disc (127). Furthermore, Holt's $(128,129,130)$ publications in the 1960s severely damaged the reputation of discography. The development of water-soluble, non-ionic contrast agents and advances in imaging technology paved the way during the 1970s and 1980s for routine clinical use of myelography, CT scanning, and MR imaging to evaluate spinal disorders (127-133). However, these imaging studies are unable to identify the pain generator in most patients with chronic spinal pain (18-19). Discography has the ability to evoke pain, which is unique among imaging studies. This provocative component has preserved the role of discography, but continues to generate controversy. Nonetheless, increased utilization of discography and increased physician-specialty representation among discographers suggests that discography has shed its pariah status (134).

The renaissance era of discography was ushered in by the concept of discogenic pain, a term synonymous with internal disc disruption (IDD). Crock (135) defined IDD as an "alteration in the internal architecture of the disc, specifically excluding the escape of the disc fragment from the confines of the space [annulus]" (135) and suggested that discography "provides the single, most valuable, special investigation in cases of disc disruption (135)."

\section{Lack of a "Gold" Standard}

Early successes with anterior lumbar fusions in patients selected by discography, reinforced Crock's opinions $(136,137)$. Nonetheless, for several reasons, pain relief following fusion surgery cannot serve as the criterion standard for discography. Technical factors may influence surgical outcomes; during an anterior lumbar interbody fusion, a symptomatic posterior annulus and posterior longitudinal ligament may be spared in order to preserve the strength of the construct (138). Surgical outcomes, irrespective of fusion type, are similar and even then, could be due to placebo or might not depend on effective fusion (138-142).

The surgical treatment of discogenic pain often centers upon stabilization. Surgeons debate the relative merits of immobilization (postero-lateral fusion), disc removal/fusion (interbody fusion), or doing both and removing all nociceptive sources (360 or circumferential fusion) (138). Discogenic pain, however, is not synonymous with "segmental instability" or "painful motion segment" (138). Segmental instability pain can emanate from spinal structures distinct from the disc.

Similarly, percutaneous intradiscal procedures cannot be used to validate or refute discography. For example, there is enough controversy centered upon the clinical outcomes and the mechanisms of action of intradiscal electrothermal therapy (IDET) that one could not use IDET to serve as the criterion standard for discography (39, 40, 143-147). Arguably, one could simply assign discography face validity, but ultimately all diagnostic tests must be investigated for accuracy.

\section{Basic Principles}

A diagnostic test is used to ascertain the disease/health status in a patient. A test may refer to any procedure that is used to gather information on the health status of an individual. The detection of disease is important in guiding therapy, particularly when therapy may reduce morbidity and mortality, and in facilitating research.

Diagnostic accuracy studies assess a diagnostic test's ability to detect the target condition. Typical features of diagnostic accuracy studies include: 1) administering the test in question (index test) and a reference standard to a series of patients; and 2) measuring how well the index test did in comparison to the reference (45).

Measurements of the index test's performance are reported as statistics: sensitivity, specificity, positive and negative predictive values, positive and negative likelihood ratios, diagnostic odds ratios, and receiver operator characteristic curves. Although these measurements are mathematically interrelated, sensitivity and specificity are relevant in the research setting where one knows, or can ascertain, the disease status of a patient. In a clinical setting where the practitioner doesn't know the disease status of a patient, the predictive values are relevant; the practitioner obtains a diagnostic test result (positive or negative) and wants to "predict" the truthfulness of the patient's test result (124, 148-150). These measurements are influenced by: 1) how one defines a positive or negative result; and 2) the prevalence of a disease in a population.

Diagnostic test results often appear as continual or ordinal data. A cutoff for normality/abnormality may have to be chosen arbitrarily. Choosing a cutoff, however, influences the test's sensitivity and specificity at each other's expense. A diagnostic test with high sensitivity, a low false negative rate, is most useful as a screening test to rule out a disease. A diagnostic test with high specificity, a low false positive rate, is most useful as a second or confirmatory test to rule in a disease (124, 148-150).

Disease prevalence affects the predictive value, i.e., the post-test probability, of a test. The pre-test probability of a disease is, by definition, the prevalence. Lowering the prevalence of a disease will increase the negative predictive value, but will decrease the positive predictive value. In a population with low disease prevalence, a negative result is more likely to be true and a positive result is more likely to be false. Raising the prevalence of a disease in a tested population will lower the negative predictive value and increase the positive predictive value. In a population with high disease prevalence, a positive value is more likely to be a true and a negative value is more likely to be a false (124, 148-150).

A study that selects the tested population (i.e., artificially controls the prevalence of disease) may obtain results that are not relevant to clinical practice. In clinical practice, one would never perform discography on an asymptomatic patient; the positive and negative predictive values of discography in an asymptomatic population will differ from those seen in clinical practice. For instance, the positive predictive value of discography in a population that does not have back pain should be 0 (all false-positives). The same positive result in a theoretical population with a $100 \%$ prevalence of discogen- 
ic pain should have a PPV of $100 \%$ (124, 148-150).

As a tool to evaluate pain, the sensitivity of discography can approach $100 \%$ in absolute and relative - relative to other imaging modalities - terms, depending on the definition of a negative result. If a negative disc is defined as one that is pain free and pathology free, then a false-negative could only occur when: 1 ) the patient is overly sedated; 2) there is an unrecognized equipment malfunction during intradiscal injection; 3) a placebo response occurs with discography; 4) intradiscal pathology is missed that could be detected by direct pathological inspection (15, 151); 5) technical failure, such as an annular injection $(77,152) ; 6)$ partial nuclear filling due to the presence of a septum or intranuclear inhomogeneity $(77,152)$; or 7) lack of continuity between the nuclear cavity and the annulus - the annulus may be prolapsed, but not the nuclear material (143); These scenarios are unlikely if discography is performed properly and post procedure CT scanning is obtained $(9,17$, $43,110)$. Perhaps a false negative could occur due to a placebo response from discography. Placebo responses have induced pain relief following intradiscal sham procedures, even though a prior intradiscal provocation caused pain (39). Such a strict definition of a negative result, however, will increase the probability of falsepositives; any evoked pain, whether concordant or not, would be positive.

Since discography, in routine practice, is performed on symptomatic patients, the pain provocation component is most important (76). This mandates that the specificity of discography be increased in order to reduce the false-positive rate. Under these circumstances, one can define true positive as evoked pain that is identical to the patient's baseline pain in a pathological IVD. Guidelines have been published to enhance the specificity of discography and these guidelines advocate assessing pain concordancy, measuring pain intensity, and identifying pain free control levels $(18,19,153)$.

\section{Discogenic Pain: Assumptions}

Before studying the diagnostic accuracy of discography and ultimately, performing a systematic review, several assumptions have to be made about the model of "discogenic" pain. Curiously, many practitioners consider these assumptions to be truths (i.e., to have face validity). It's the disc, stupid! These assumptions include: 1) discogenic pain exists, which implies that therapies directed at the intervertebral disc can effectively treat a subset of patients with chronic spine pain; 2) discogenic pain has a structural/pathological basis that can be imaged; and 3) discogenic pain can be reproduced by experimentally inducing physiological intradiscal loads. All three assumptions have been challenged.

In principle, therapies targeted at the IVD appear promising (154-160). In reality, these treatments are not the magic bullets one would expect $(39,139,161$ 164). The ability to provoke pain with discography is self-evident, but one cannot summarily claim the disc to be the putative pain generator. "Discogenic" pain is inferred because of several factors: 1) the presence of "painful" discs that demonstrate neural ingrowth, neovascularization, and a zone of granulation tissue through the posterior annulus (165-168); 2) immunohistochemical evidence of pain biomarkers (e.g., Substance P, nerve growth factor, neurofilament, vasoactive intestinal peptide) (166-168); 3) high innervation densities clustered around the endplates and annulus fibrosis (169); 4) the presence of inflammation, as suggested by tumor necrosis factor alpha (170, 171); and, 5) the presence of dense extradiscal neural plexi and definable neural pain pathways (30-35, 172, 173).

Unfortunately, inference is not proof. Routine real time imaging of spinal pain processing is unavailable. So, one cannot know, in real time, whether the disc is the source of a patient's pain. Lastly, how does mechanical loading induce discogenic pain? Specifically, how is a physiologically normal stimulus (pressure) transduced into a pain signal?

Blunt pressure (i.e., forces distributed over a large surface area) can activate deep afferent nociceptors in healthy volunteers (174). These afferents are poly modal and respond to mechanical stimuli (174). In patients with chronic pain syndromes, afferent fibers become peripherally sensitized to lower threshold mechanical stimuli. This mechanical hyperalgesia occurs in the stimulated area (primary) and in uninvolved areas (secondary). Enhanced pain sensitivity may also occur secondarily to central sensitization (174). Polymodal mechanoreceptors are present in the outer annulus of the IVD (175). Although these receptors may play a role in spinal proprioception, in preserving spinal tone, and in maintaining spinal reflexes, they may be capable of nociception (175). These receptors are more commonly found in patients with low back pain compared to pain free scoliotic controls (175). The association between the presence of mechanoreceptors and the occurrence of pain, although plausible, is speculative (175).

One can question whether similar processes are relevant, yet confounding, to diagnosing discogenic pain with discography: 1) Could discogenic pain occur due to pressure induced mechanical hyperalgesia or evoked allodynia?; 2) could pain, with intradiscal pressurization, occur in healthy volunteers and not be considered a false-positive?; and, 3) could pain, secondary to mechanical hyperalgesia, be evoked in control discs and not be considered a false-positive?

\section{Pressure Pain Thresholds}

Algometry and palpation have construct validity in the assessment of pressure-induced pain $(174,176)$. Pressure pain threshold (PPT) is defined as the minimum pressure that induces pain (176). PPTs can be measured with a pressure algometer and are used to evaluate a variety of myofascial pain syndromes: arthritis, whiplash, ankylosing spondylitis, temporomandibular joint dysfunction, and tension-type headache $(165,166)$.

PTs have large intra- and inter-individual variability $(176,177)$. In healthy volunteers, Prushansky (176) reported cervical area PPTs with means ranging from 140-200 kPas, approximately 20-35 psi. In the distal limbs of healthy volunteers, average deep pain thresholds range from 520-615 kPas, approximately 75-90 psi (177).

In patients with chronic low back pain, PPTs correlate with a patient's baseline functional status and pain intensity (178). The mean pressures needed to induce intense pain are higher in healthy controls, as compared to patients with chronic low back pain and fibromyalgia. To induce moderate or severe pain in locations similar to a patient's pain, pressures of $38.4 \mathrm{psi}\left(2.7 \mathrm{~kg} / \mathrm{cm}^{2}\right)$, and 69.7 psi $\left(4.9 \mathrm{~kg} / \mathrm{cm}^{2}\right)$, respectively, are needed (179). However, the standard deviations for these means were large enough that PPTs overlapped between all three groups, i.e., patients could develop pain at similar PPTs (179). The authors did not challenge 
the construct validity of algometry despite this overlap of pressures. If discography is considered to be a PPT assessment, then "discogenic" pain may be induced in healthy controls $(61-63,66,91)$ and not necessarily challenge the construct validity of discography.

In a healthy, asymptomatic volunteer, baseline pressure measurements in the L4-5 disc will vary with different activities $(180,181): 43.5$ psi with relaxed sitting, 101 psi with axial rotation, and 160 psi with forward flexion while standing. The maximum pressure was $334 \mathrm{psi}$, recorded while the volunteer held a 20 $\mathrm{kg}$ object away from his center of gravity $(180,181)$. This volunteer did not have back pain during the experiment. Such large pressure excursions are not needed to produce pain in symptomatic patients undergoing discography; often a pressure differential of 100 psi is sufficient (61-63, $66,72,91)$.

O'Neill and Kurgansky (91) have postulated that PPT assessments of the intervertebral disc may identify two distinct symptomatic subgroups. One subgroup may have PPTs that are similar to asymptomatic patients and are classified as minimally sensitive. In this group, the false-positive rate can be estimated. The caveat in using the term false-positive is that this term refers to the diagnosis of discogenic pain. However, as discussed earlier, the PPT is a characteristic of all tissues and should not, in isolation, be used to determine whether a tissue is pathological or diseased - hence, the overlap of PPTs between asymptomatic and symptomatic patients.

Sophistry (182) suggests that a reduction in PPT depends on tissue characteristics (nociceptor ingrowth, peripheral sensitization, disc morphology) and pain processing (central sensitization) (91), but one cannot prove this with a single isolated PPT assessment. One cannot prove this even if this PPT is compared to PPTs in asymptomatic patients. Ideally, one would have to assess the PPT in the same patient longitudinally: first, when the patient is asymptomatic, and then when the patient is symptomatic. This methodology should be applied to a large number of patients in order to determine how much of a PPT differential is clinically relevant. Unfortunately, such methodology would be impractical and unethical. Until then, however, relying on intradiscal PPTs from a small group of asymptomatic patients may not be a valid means of determining whether an isolated PPT in a patient is abnormal or normal.

\section{Intradiscal Distention}

Adams et al (183) studied the dispersal of an aqueous solution following intradiscal injection. The resultant intradiscal pressure will depend on the deformability of the endplates and annulus. Initially, endplates bulge vertically and raise IVD height, because the endplates are more deformable than the annulus (183). The dye/contrast mixture will pool near the endplate and not at the nuclear/annular junction (183). The aqueous mixture will eventually diffuse into the nucleus pulposus (183). Endplate deflection with intradiscal pressurization has been corroborated by other investigators (184). One must wonder, then, whether intradiscal pressures become dissipated before reaching the annulus.

Could the pain during discography be due to peak pressures that exceed the endplate PPT? The high innervation density of the endplate (169), the initiation of disc degeneration following endplate fractures (26), and the association of severe back pain with endplate damage $(117,185,186)$, support this contention. Weishaupt et al (117) suggests that moderate and severe endplate abnormalities may predict discogenic pain in symptomatic low back pain patients. Perhaps then, during discography, the simultaneous provocation of pain and demonstration of a posterior annular tear may simply be coincidence and not imply causality. Nonetheless, whether discogenic pain is due to endplate abnormalities or not is an issue that remains unsolved (184). Kokkonen et al (187) suggests that annular tears and concordant pain during discography are not associated with endplate degeneration. Saifuddin et al (97) argues that endplates are unlikely to be the source of radiating discogenic pain. In their study, anterior annular tears were not associated with radiating pain, as were posterior tears. If the endplates were the source of pain, then provocation should be equally distributed between patients with anterior and posterior tears.

Could peak pressures be transmitted to the annulus and exceed annular PPTs? The intranuclear pressure that is transmitted during discography to an annular tear may differ from those pressures transmitted to an intact annulus. An annular tear may be receiving high peak pressures and simultaneously have a reduced PPT, secondary to the factors mentioned above. Using cadavers, Adams et al (183) demonstrated that intranuclear pressures are reduced with disc degeneration and these pressures are transmitted to the torn posterior annulus. In symptomatic patients, high stress concentrations may develop in the torn posterior annulus and cause pain (183). Stress profilometry, in subjects with chronic lumbar discogenic pain, has corroborated this cadaveric data (188). Symptomatic patients may demonstrate depressurization of the nucleus, multiple stress concentrations in the posterior annulus, or broadening of the posterior annulus (188).

Lee et al (189) studied the relationship between intradiscal pressure and outer annular pressure in porcine intervertebral discs, with and without experimentally-induced annular tears. Intradiscal injections into discs with an intact annulus resulted in a sharp increase in intradiscal pressure, but pressures in the outer annulus remained low. In discs with annular tears, higher pressures were noted in the outer annulus. Mean pressures at the central nucleus pulposus, the outer third of intact annuli, and the torn annuli were 93.4+/-40.9 psi, $14.8+/-1.9$ psi and $85.7+/$ $-24.8 \mathrm{psi}$, respectively. In human discs without observable radial tears, the intrinsic pressure averages 25 psi in an unweighted position (72). In discs with radial tears, the average unweighted intrinsic pressure is lower at 15 psi (72). Intradiscal volumetric injections will induce a parallel rise between intranuclear and intraannular pressures in those discs with a torn annulus. This data is consistent with the findings by Adams et al (183), but differs from McNally et al (188) in that the nucleus pulposus remains pressurized. In any event, absolute intradiscal (intranuclear) pressures may not represent pressures at the posterior annulus and pressures at a torn posterior annulus may demonstrate unpredictable pressure peaks $(183,188$, 189). The torn posterior annulus may deform and broaden, as a consequence of these "stress" peaks. (188).

Annular tears may explain, after all, why discography evokes pain in pathologically torn discs compared to normal discs. Alternatively, multiple sources around the IVD may be causing pain in concert: endplates, annulus, microtrabec- 
ular trauma, bony strains, and bony irritation (184).

\section{Discogenic Pain: Caveats}

Annular tears and endplate damage may be plausible etiologies for discogenic pain, because they fulfill Bogduk's [anatomic/structural] criteria (190) for pain generators: 1) the structure must have a nerve supply; 2) the structure must be capable of producing the patient's pain; and, 3 ) the structure must be susceptible to disease or injury. Unfortunately, such criteria conflict with modern theories about pain processing. Bogduk's criteria (190) may be easily fulfilled in the search for structures that cause acute pain, but not with chronic pain. Anatomic and structural diagnoses are often inaccurate in identifying the etiology of a patient's chronic pain.

Discogenic pain may be more complicated than a pathological disc (61). Genetic, psychological, and neurobiological mechanisms may be at play $(61,181)$. Polymorphisms in the interleukin-one locus and inflammatory mechanisms involving TNF-alpha, IL-I, and IL-8, may be responsible (170, 192-194). Woolf (195) suggested that chronic pain is a disease of the nervous system that involves peripheral and central sensitization. The complexity of disc innervation and the lack of consistent correlation between disc pathology and pain (28-35) suggest that practitioners should not look at the disc in isolation.

Even if one is not convinced of scientific theories, clinical and epidemiological studies challenge this structural/anatomic model of discogenic pain. Back pain does not necessarily worsen with age, but degeneration does $(196,197)$. Disc degeneration does not represent a pathological state, but occurs as a part of aging - starting in the second decade of our lives (26, 191). Segmental instability and degenerative disc disease have both been linked to chronic spinal pain (196-199): (1) pain that worsens with standing correlates with the severity of degeneration (196); and (2) pain that worsens with sitting, but abates with standing is associated with instability (198). However, degeneration and instability are present in asymptomatic patients $(198,200)$.

Kirkaldy-Willis postulated a "restabilization phase" in disc degeneration that has been supported by radiological (201) and biomechanical studies (131,
199, 202). In degenerative spondylolisthesis, restabilization is associated with pain relief (203). Curiously, surgical spine stabilization in chronic low back pain does not always work $(94,139)$. Disc removal and fusion do not improve the results of stabilization alone $(94,139)$. If discogenic pain occurs because of intradiscal/ annular neural mechanisms rather than structural problems (165-169), one would expect better results upon disc removal or neurolysis $(39,139,154-158)$, as compared to posterolateral fusion. This has not borne out in randomized controlled trials (139). The introduction of total disc replacements, Graf ligamentoplasty, and the Dynesys system confounds the problem further: motion preservation and "soft" stabilization may have outcomes that are comparable to motion stabilization $(154-157,204,205)$. This represents a paradoxical paradigm shift in the surgical treatment of discogenic pain. Collectively, this literature suggests that an exclusively anatomical/structural model of spine pain is suspect.

\section{Discogenic Pain: Analogies}

Several authors challenge the concept that a "pain generator" can be confined to a discrete anatomic structure (61, $195,206,207)$. Woolf (195) has proposed that a disease or anatomic-based classification of pain be replaced with a neurobiological mechanism-based classification. Advances in pain imaging, with respect to PET scanning and functional MR imaging, underscore the complexity of pain processing (208-210). Imaging pain is distinct from imaging a structure and inferring that a structure is the cause of pain.

In irritable bowel syndrome, rectal balloon distention of the sigmoid can evoke pain compared to controls. In this condition, pressure-evoked pain is thought to be due to altered sensory processing. These lowered sensory thresholds may be due to peripheral, spinal, and supraspinal sensitization (210). Pain intensity ratings may be exaggerated due to hypervigilance. This increased selective attention to potentially threatening stimuli is a central component of sensitization (210). In this model of pain, the rectum is not the only "pain generator," per se, and one should not infer that removing or surgically treating the rectum would treat the pain.

A similar conceptual framework may apply to discography and "discogenic" pain. Giesecke et al (179) demon- strated that if equal amounts of pressure were applied to their patients, functional MRI could detect five common regions of neuronal activation in pain-related cortical areas, in the chronic low back pain and fibromyalgia patients, but not the asymptomatic groups. Activation in the symptomatic groups occurred in the contralateral primary and secondary [S2] somatosensory cortices, the inferior parietal lobule, the cerebellum, and the ipsilateral S2 somatosensory cortex. In the asymptomatic patients, only the contralateral S2 somatosensory cortex is activated. If subjects in all three groups receive different amounts of pressure that are sufficient to evoke subjectively equal pain, then common neuronal areas are activated (179). Augmented central processes are involved in chronic low back pain (179), but there may be overlap between asymptomatic and symptomatic patients. Despite this paradigm, there is no readily available way to measure these pain processes in the individual patient $(211,212)$.

\section{Discogenic Pain: Convictions}

Until we can routinely measure pain processing, we have no choice but to rely on existing classifications of spinal pain. Despite the limitations of the anatomical/ structural model of spine pain, this model is most widely believed by interventional pain physicians and spine surgeons. Discography is considered to be the criterion standard for diagnosing discogenic pain (191). The greatest problem faced by discographers, then, stems from how discography can be optimized to best select those patients in whom the pain emanates primarily from the disc - as opposed to "non-specific factors." The ultimate goal is to identify that subset of patients who will most likely succeed from surgical and non-surgical disc treatment.

\section{Discography}

The Executive Committee of the North American Criteria developed a position statement on discography (18). "Discography is an important procedure in current use in the field of spine care and [should not be removed]: it provides information which [cannot] be obtained by other methods. At a minimum, the modern practice of discography should consist of proper technique, an assessment of the intensity and concordancy of evoked pain, and an assessment by postdiscography CT-scanning of intradiscal 
architecture."

Post-discography CT scanning, initially introduced by McCutcheon and Thompson (21), can confirm accurate intranuclear placement of contrast spread. Yasuma et al (151) demonstrated that atypical discograms were often due to technical errors, such as intraannular injections. These can be missed in the absence of a CT scan. Of processes involved in DDD, annular fissures, particularly radial fissures, are the most important as an etiology of chronic spine pain (14). This underscores the importance of an axial IVD view (213). CT-discography provides the best axial IVD view $(17,20)$. In our review, we could not mandate a requirement for CT scanning, since many well designed studies would have been excluded.

Overall, discography is a useful imaging tool. Intradiscal pathology may be missed by other studies. A post-discography CT scan may provide useful, additional information, particularly to differentiate annular tears from annular disruption. Discography can produce pain in patients with mild or chronic low back pain, with a chronic pain disorder, or with no pain, at all. Discography, rarely, if ever, provokes pain in morphologically normal discs. Annular tears, particularly those extending to the outer annulus, are often associated with discographically provoked pain. Degenerative disc changes are not necessarily associated with pain provocation. However, progressive degeneration is associated with dissimilar and similar pain provocation.

Discography cannot predict future back pain problems or disability in asymptomatic patients. Discography should not be used as a screening test for employment. Patients with persistent back pain following discography may have emotional and psychological problems. False-positives may be reduced during discography if only patients with normal psychometric profiles and without other chronic pain syndromes are selected. The background incidence of minor back pain that is discogenically mediated may be high and may confound the identification of those patients with severe discogenic pain.

If one considers discography to be a form of PPT, then one would expect both normal and abnormal discs to produce pain. All tissues can evoke pain if exposed to sufficiently high pressures. In this sce- nario, one cannot arbitrarily decide between a true-positive versus a false-positive, in an a priori fashion; in a symptomatic low back pain population, we cannot define false-positive rates based on pain provocation in an asymptomatic population. Rather, to define normality, one would have to tabulate PPTs in a large population based fashion. One example, as suggested by O'Neill and Kurgansky (91) would be to plot the number of individuals ( $\mathrm{y}$-axis) versus PPTs ( $\mathrm{x}$ axis). This method could be applied prospectively to an asymptomatic population with normal psychological profiles, an asymptomatic population with abnormal psychological profiles, an asymptomatic population with chronic non-spinal pain, and a symptomatic spinal pain population. Based on these population distributions, one could then define the probability of a true- or false-positive in an individual patient. Similar strategies are used in screening mothers during their first trimester - the triple screen - to determine their risk of delivering a baby with Down's syndrome $(214,215)$.

We can extend this concept further. We could define discography results as numerical values rather than as a binary, positive or negative, result. In other words, if discography results were reported in terms of PPTs, the sensitivity and specificity would change at different PPT cutoffs. Then, the sensitivity (y-axis) could be plotted versus 1-specificity ( $\mathrm{x}$-axis) by using the results obtained at different PPT cutoffs. This will define a receiver operator characteristic (ROC) curve, which is an effective method for evaluating the quality of a diagnostic test (148-150). If the ROC curve passes upwards to the left, the diagnostic test is nearly perfect in distinguishing disease from no disease. If the ROC curve is diagonal, the diagnostic test has no value above simply knowing the prevalence of the disease in actually detecting the disease $(124,148-150)$. To generate an ROC curve at this juncture would be premature, since only a few papers have prospectively collected pressure pain threshold data during discography.

In the absence of population-based data, the ability of discography to provoke pain should not be surprising. The greater paradoxes are: 1) whether discography can select patients for treatment; 2) whether discography can prognosticate outcomes following surgical and non-sur- gical treatments; and 3) whether symptomatic internal disc disruption exists, as a discrete anatomic/structural entity, in isolation from peripheral and central pain processes.

Future research is needed that investigates the precise mechanisms of how discography induces pain and how this correlates with functional activities. Also needed is external validation - not based on subjective pain assessments - of the ability of discography to precisely identify the disc as the pain generator. In those patients with chronic spinal pain, perhaps advances in functional imaging, pain processing neurobiology, and clinical biomarkers can complement discography, in ascertaining the relative contribution of the IVD to pain. Lastly, population-based data on intradiscal pressure pain thresholds, both in asymptomatic and symptomatic patients, would enable practitioners to distinguish between true- and false-positives in individual patients. Ideally, such pressure pain thresholds could be used to generate a receiver operator characteristic curve to better evaluate the diagnostic accuracy of discography.

In the interim, questioning the validity of discography warrants questioning the role of the intervertebral disc as a discrete pain generator, or more specifically, challenges the concept of symptomatic internal disc disruption. If one considers discography to be a useless test, then one may have to abandon the concept of the IVD as a discrete pain generator and abandon the pursuit of intradiscal therapies, whether surgical or non-surgical.

\section{Conclusion}

There is strong evidence for the utility of discography as an IVD imaging tool. There is strong evidence that intradiscal distention can produce pain. There is strong evidence supporting the role of discography in identifying patients with chronic lumbar discogenic pain. There is moderate evidence supporting the role of discography in identifying patients with chronic cervical discogenic pain. There is limited evidence supporting the role of discography in identifying patients with chronic thoracic discogenic pain. 
Author Affiliation:

Rinoo V. Shah, MD

Assistant Professor and Co-Director

Pain Division

Department of Anesthesiology

Interventional Pain Institute

Texas Tech University Health Sciences

Center

4430 South Loop 289

Lubbock, TX 79414

E-mail: rinoo_shah@yahoo.com

\section{Clifford R. Everett, MD}

Assistant Professor

Department of Orthopaedics

and Physical Medicine and

Rehabilitation

University of Rochester Medical Center

601 Elmwood Avenue, Box 65

Rochester, NY 14642

E-mail: clifford_everett@URMC.Roche ster.edu

Anne Marie McKenzie-Brown, MD

Assistant Professor of Anesthesiology

Division Director, Division of Pain

Medicine

Emory Department of Anesthesiology

Emory Center for Pain Medicine

550 Peachtree Street, NE

Atlanta GA 30308

E-mail: anne_marie_mckenzie-

brown@emory.org

\section{Nalini Sehgal, MD}

Medical Director

UW Interventional Pain

Program

University of Wisconsin

Medical School

Dept, of Orthopedics and

Rehabillitation

600 Highland Avenue, $\# 2424$

Madison, WI 53792-3228

E-mail: n.sehgal@hosp.wisc.edu

\section{REFERENCES}

1. Smith GW, Nichols P Jr. The technic of cervical discography. Radiology 1957; 68: 718-720.

2. Cloward RB. The anterior surgical approach to the cervical spine: the Cloward Procedure: past, present, and future. The presidential guest lecture, Cervical Spine Research Society. Spine 1988; 13:823827.

3. Cloward RB. Anterior herniation of a ruptured lumbar intervertebral disk; comments on the diagnostic value of the disk- ogram. AMA Arch Surg 1952; 64:457-463.

4. Lindblom K. Technique and results of diagnostic disc puncture and injection (discography) in the lumbar region. Acta Orthop Scand 1951; 20:315-326.

5. Lindblom K. Technique and results in myelography and disc puncture. Acta Radiol 1950; 34:321-330.

6. Antti-Poika I, Soini J, Tallroth K, Yrjonen T, Konttinen YT. Clinical relevance of discography combined with CT scanning. A study of 100 patients. J Bone Joint Surg Br 1990; 72:480-485.

7. Buirski G, Silberstein M. The symptomatic lumbar disc in patients with low-back pain. Magnetic resonance imaging appearances in both a symptomatic and control population. Spine 1993; 18:1808-1811.

8. Brightbill TC, Pile N, Eichelberger RP, Whitman M Jr. Normal magnetic resonance imaging and abnormal discography in lumbar disc disruption. Spine 1994; 19:10751077.

9. Birney TJ, White JJ Jr, Berens D, Kuhn G. Comparison of MRI and discography in the diagnosis of lumbar degenerative disc disease. J Spinal Disord 1992; 5:417-423.

10. Gibson MJ, Buckley J, Mawhinney R, Mulholland RC, Worthington BS. Magnetic resonance imaging and discography in the diagnosis of disc degeneration. A comparative study of 50 discs. J Bone Joint Surg $\mathrm{Br}$ 1986; 68:369-373.

11. Bogduk N, Modic MT. Lumbar discography. Spine 1996; 21:402-404.

12. Yu SW, Haughton VM, Sether LA, Wagner $M$. Comparison of MR and diskography in detecting radial tears of the anulus: $\mathrm{A}$ postmortem study. AJNR Am J Neuroradiol 1989; 10:1077-1081.

13. Abdelwahab IF, Gould ES. The role of diskography after negative postmyelography CT scans: retrospective review. AJNR Am J Neuroradiol 1988; 9:187-190.

14. Videman T, Nurminen M. The occurrence of anular tears and their relation to lifetime back pain history: a cadaveric study using barium sulfate discography. Spine 2004; 29:2668-2676.

15. Adams MA, Dolan P, Hutton WC. The stages of disc degeneration as revealed by discograms. J Bone Joint Surg Br 1986; 68:3641.

16. Milette PC, Fontaine S, Lepanto L, Cardinal $E$, Breton G. Differentiating lumbar disc protrusions, disc bulges, and discs with normal contour but abnormal signal intensity. Magnetic resonance imaging with discographic correlations. Spine 1999; 24:4453.

17. Bernard TN Jr. Lumbar discography followed by computed tomography. Refining the diagnosis of low-back pain. Spine 1990; 15:690-707.

18. Guyer RD, Ohnmeiss DD; NASS. Lumbar discography. Spine J 2003; 3:11S-27S.

19. Guyer RD, Ohnmeiss DD. Lumbar discography. Position statement from the North
American Spine Society Diagnostic and Therapeutic Committee. Spine 1995; 20: 2048-2059.

20. Sachs BL, Vanharanta H, Spivey MA, Guyer RD, Videman T, Rashbaum RF, Johnson RG, Hochschuler SH, Mooney V. Dallas discogram description. A new classification of $\mathrm{CT} /$ discography in low-back disorders. Spine 1987; 12:287-294.

21. McCutcheon ME, Thompson WC III. CT scanning of lumbar discography. A useful diagnostic adjunct. Spine 1986; 11:257259.

22. Block AR, Vanharanta H, Ohnmeiss DD, Guyer RD. Discographic pain report. Influence of psychological factors. Spine 1996; 21:334-338.

23. Adams MA, Freeman BJ, Morrison HP, Nelson IW, Dolan P. Mechanical initiation of intervertebral disc degeneration. Spine 2000; 25:1625-1636.

24. Battie MC, Videman T, Gibbons LE, Fisher LD, Manninen H, Gill K. 1995 Volvo Award in clinical sciences. Determinants of lumbar disc degeneration. A study relating lifetime exposures and magnetic resonance imaging findings in identical twins. Spine 1995; 20:2601-2612.

25. Battie MC, Videman T, Parent E. Lumbar disc degeneration: epidemiology and genetic influences. Spine 2004; 29:26792690.

26. Rajasekaran S, Babu JN, Arun R, Armstrong BR, Shetty AP, Murugan S. ISSLS prize winner: A study of diffusion in human lumbar discs: a serial magnetic resonance imaging study documenting the influence of the endplate on diffusion in normal and degenerate discs. Spine 2004; 29: 2654-2667.

27. Moneta GB, Videman T, Kaivanto K, Aprill C, Spivey M, Vanharanta H, Sachs BL, Guyer RD, Hochschuler SH, Raschbaum RF, Mooney V. Reported pain during lumbar discography as a function of anular ruptures and disc degeneration. A re-analysis of 833 discograms. Spine 1994; 19:19681974.

28. Vanharanta H, Sachs BL, Spivey MA, Guyer RD, Hochschuler SH, Rashbaum RF, Johnson RG, Ohnmeiss D, Mooney V. The relationship of pain provocation to lumbar disc deterioration as seen by $\mathrm{CT} / \mathrm{discog}$ raphy. Spine 1987; 12:295-298.

29. Slipman CW, Patel RK, Zhang L, Vresilovic E, Lenrow D, Shin C, Herzog R. Side of symptomatic annular tear and site of low back pain: is there a correlation? Spine 2001; 26:E165-E169.

30. Aoki Y, Ohtori S, Takahashi K, Ino H, Takahashi Y, Chiba T, Moriya H. Innervation of the lumbar intervertebral disc by nerve growth factor-dependent neurons related to inflammatory pain. Spine 2004; 29 : 1077-1081.

31. Aoki Y, Takahashi Y, Takahashi K, Chiba T, Kurokawa M, Ozawa T, Moriya H. Sensory innervation of the lateral portion of the lumbar intervertebral disc in rats. Spine J 
2004; 4:275-280.

32. Aoki Y, Takahashi Y, Ohtori S, Moriya H, Takahashi K. Distribution and immunocytochemical characterization of dorsal root ganglion neurons innervating the lumbar intervertebral disc in rats: a review. Life Sci 2004; 74:2627-2642.

33. Takahashi Y, Chiba T, Kurokawa M, Aoki Y, Takahashi K, Yamagata M. Stereoscopic structure of sensory nerve fibers in the lumbar spine and related tissues. Spine 2003; 28:871-880.

34. Nakamura SI, Takahashi K, Takahashi Y, Yamagata M, Moriya H. The afferent pathways of discogenic low-back pain. Evaluation of L2 spinal nerve infiltration. J Bone Joint Surg Br 1996; 78:606-612.

35. Nakamura S, Takahashi K, Takahashi Y, Morinaga T, Shimada Y, Moriya H. Origin of nerves supplying the posterior portion of lumbar intervertebral discs in rats. Spine 1996; 21:917-924.

36. Urasaki T, Muro T, Ito S, Hattori Y, Ozaki S. Consistency of lumbar discograms of the same disc obtained twice at a 2-week interval: influence of needle tip position. J Orthop Sci 1998; 3:243-251.

37. Thalgott JS, Albert TJ, Vaccaro AR, Aprill CN, Giuffre JM, Drake JS, Henke JP. A new classification system for degenerative disc disease of the lumbar spine based on magnetic resonance imaging, provocative discography, plain radiographs and anatomic considerations. Spine J 2004; 4: $167 \mathrm{~S}-172 \mathrm{~S}$.

38. Shuff C, An HS. Artificial disc replacement: the new solution for discogenic low back pain? Am J Orthop 2005; 34:8-12.

39. Pauza KJ, Howell S, Dreyfuss P, Peloza JH, Dawson K, Bogduk N. A randomized, placebo-controlled trial of intradiscal electrothermal therapy for the treatment of discogenic low back pain. Spine J 2004; 4:2735 .

40. Saal JA, Saal JS. Intradiscal electrothermal treatment for chronic discogenic low back pain: prospective outcome study with a minimum 2-year follow-up. Spine 2002; 27:966-973.

41. Huang TS, Zucherman JF, Hsu KY, Shapiro M, Lentz D, Gartland J. Gadopentetate dimeglumine as an intradiscal contrast agent. Spine 2002; 27:839-843.

42. Grubb SA, Kelly CK. Cervical discography: clinical implications from 12 years of experience. Spine 2000; 25:1382-1389.

43. Simmons JW, Aprill CN, Dwyer AP, Brodsky $A E$. A reassessment of Holt's data on: "The question of lumbar discography." Clin Orthop Relat Res 1988; 237:120-124.

44. West S, King V, Carey TS, Lohr KN, McKoy, N, Sutton SF, Lux L. Systems to rate the strength of scientific evidence. Evidence Report/Technology Assessment No. 47 University of North Carolina: Agency for Healthcare Research and Quality. AHRQ Publication No. 02-E016; April 2002.

45. Whiting P, Rutjes AW, Reitsma JB, Bossuyt PM, Kleijnen J. The development of QUA-
DAS: a tool for the quality assessment of studies of diagnostic accuracy included in systematic reviews. BMC Med Res Methodol 2003; 3:25.

46. Manchikanti L, Abdi S, Lucas L. Evidence Synthesis and Development of Guidelines in Interventional Pain Management, An Invited Review. Pain Physician 2005; 8:7386.

47. Gill K, Blumenthal SL. Functional results after anterior lumbar fusion at $\mathrm{L}_{5}-\mathrm{S}_{1}$ in patients with normal and abnormal MRI scans. Spine 1992; 17:940-942.

48. Brodsky AE, Binder WF. Lumbar discography. Its value in diagnosis and treatment of lumbar disc lesions. Spine 1979; 4:110120.

49. Esses SI, Botsford DJ, Kostuik JP. The role of external spinal skeletal fixation in the assessment of low-back disorders. Spine 1989; 14:594-601.

50. Jaffray D, O’Brien JP. Isolated intervertebral disc resorption. A source of mechanical and inflammatory back pain? Spine 1986; 11:397-401.

51. O’Neill CW, Kurgansky ME, Derby R, Ryan DP. Disc stimulation and patterns of referred pain. Spine 2002; 27:2776-2781.

52. Sandhu HS, Sanchez-Caso LP, Parvataneni HK, Cammisa FP Jr, Girardi FP, Ghelman B. Association between findings of provocative discography and vertebral endplate signal changes as seen on MRI. J Spinal Disord 2000; 13:438-343.

53. Shinomiya K, Nakao K, Shindoh S, Mochida K, Furuya K. Evaluation of cervical diskography in pain origin and provocation. $J$ Spinal Disord 1993; 6:422-426.

54. Vamvanij V, Fredrickson BE, Thorpe JM, Stadnick ME, Yuan HA. Surgical treatment of internal disc disruption: an outcome study of four fusion techniques. J Spinal Disord 1998; 11:375-382.

55. Whitecloud TS III, Seago RA. Cervical discogenic syndrome. Results of operative intervention in patients with positive discography. Spine 1987; 12:313-316.

56. Aprill C, Bogduk N. High-intensity zone: A diagnostic sign of painful lumbar disc on magnetic resonance imaging. $\mathrm{Br} /$ Radiol 1992; 65:361-369.

57. Bogduk N, Aprill C. On the nature of neck pain, discography and cervical zygapophysial joint blocks. Pain 1993; 54:213-217.

58. Braithwaite I, White J, Saifuddin A, Renton P, Taylor BA. Vertebral end-plate (Modic) changes on lumbar spine MRI: Correlation with pain reproduction at lumbar discography. Eur Spine J 1998; 7:363-368.

59. Carragee EJ, Chen Y, Tanner CM, Hayward C, Rossi M, Hagle C. Can discography cause long-term back symptoms in previously asymptomatic subjects? Spine 2000; 25:1803-1808.

6o. Carragee EJ, Barcohana B, Alamin T, van den Haak E. Prospective controlled study of the development of lower back pain in previously asymptomatic subjects undergoing experimental discography. Spine
2004; 29:1112-1117

61. Carragee EJ, Alamin TF, Miller J, Grafe M. Provocative discography in volunteer subjects with mild persistent low back pain. Spine J 2002; 2:25-34.

62. Carragee EJ, Chen Y, Tanner CM, Truong T, Lau E, Brito JL. Provocative discography in patients after limited lumbar discectomy: A controlled, randomized study of pain response in symptomatic and asymptomatic subjects. Spine 2000; 25:3065-3071.

63. Carragee EJ, Tanner CM, Yang B, Brito JL, Truong T. False-positive findings on lumbar discography. Reliability of subjective concordance assessment during provocative disc injection. Spine 1999; 24:25422547.

64. Zahn PK, Pogatzki EM, Brennan TJ. Mechanisms for pain caused by incisions. Reg Anesth Pain Med 2002; 27:514-516.

65. Maigne JY, Doursounian L. Entrapment Neuropathy of the medial superior cluneal nerve: Nineteen cases surgically treated, with a minimum of 2 years follow-up. Spine 1997; 22:1156-1159.

66. Carragee EJ, Tanner CM, Khurana S, Hayward C, Welsh J, Date E, Truong T, Rossi M, Hagle $C$. The rates of false-positive lumbar discography in select patients without low back symptoms. Spine 2000; 25:13731380.

67. Carragee EJ, Paragioudakis SJ, Khurana S. 2000 Volvo Award winner in clinical studies: Lumbar high-intensity zone and discography in subjects without low back problems. Spine 2000; 25:2987-2992.

68. Cohen SP, Larkin T, Fant GV, Oberfoell R, Stojanovic $M$. Does needle insertion site affect diskography results? A retrospective analysis. Spine 2002; 27:2279-2283.

69. Colhoun E, McCall IW, Williams L, Cassar Pullicino VN. Provocation discography as a guide to planning operations on the spine. J Bone Joint Surg Br 1988; 70:267-271.

70. Collins CD, Stack JP, O'Connell DJ, Walsh M, McManus FP, Redmond OM, Ennis JT. The role of discography in lumbar disc disease: a comparative study of magnetic resonance imaging and discography. Clin Radiol 1990; 42:252-257.

71. Connor PM, Darden BV II. Cervical discography complications and clinical efficacy. Spine 1993; 18:2035-2038.

72. Derby R, Howard MW, Grant JM, Lettice JJ, Van Peteghem PK, Ryan DP. The ability of pressure-controlled discography to predict surgical and nonsurgical outcomes. Spine 1999; 24:364-371.

73. Donelson R, Aprill C, Medcalf R, Grant W. A prospective study of centralization of lumbar and referred pain. A predictor of symptomatic discs and anular competence. Spine 1997; 22:1115-1122.

74. Greenspan A, Amparo EG, Gorczyca DP, Montesano PX. Is there a role for diskography in the era of magnetic resonance imaging? Prospective correlation and quantitative analysis of computed tomographydiskography, magnetic resonance imag- 
ing, and surgical findings. I Spinal Disord 1992; 5:26-31.

75. Heggeness MH, Watters WC III, Gray PM Jr. Discography of lumbar discs after surgical treatment for disc herniation. Spine 1997; 22:1606-1609.

76. Horton WC, Daftari TK. Which disc as visualized by magnetic resonance imaging is actually a source of pain? A correlation between magnetic resonance imaging and discography. Spine 1992; 17:S164-S171.

77. Ito M, Incorvaia KM, Yu SF, Fredrickson BE, Yuan HA, Rosenbaum AE. Predictive signs of discogenic lumbar pain on magnetic resonance imaging with discography correlation. Spine 1998; 23:1252-1258.

78 Lam KS, Carlin D, Mulholland RC. Lumbar disc high-intensity zone: the value and significance of provocative discography in the determination of the discogenic pain source. Eur Spine J 2000; 9:36-41.

79 Madan S, Gundanna M, Harley JM, Boeree NR, Sampson M. Does provocative discography screening of discogenic back pain improve surgical outcome? J Spinal Disord Tech 2002; 15:245-251.

8o. Maezawa S, Muro T. Pain provocation at lumbar discography as analyzed by computed tomography/discography. Spine 1992; 17:1309-1315.

81. Manchikanti L, Singh V, Pampati VS, Fellows B, Beyer C, Damron K, Cash KA. Provocative discography in low back pain patients with or without somatization disorder: A randomized prospective evaluation. Pain Physician 2001; 4:227-239.

82. Manchikanti L, Singh V, Pampati VS, Damron KS, Barnhill RC, Beyer C, Cash KA. Evaluation of the relative contributions of various structures in chronic low back pain. Pain Physician 2001; 4:308-316.

83. McFadden JW. The stress lumbar discogram. Spine 1988; 13:931-933.

84. Milette PC, Fontaine S, Lepanto L, Breton G. Radiating pain to the lower extremities caused by lumbar disk rupture without spinal nerve root involvement. AJNR Am J Neuroradiol 1995; 16:1605-1613.

85. Motimaya A, Arici M, George D, Ramsby G. Diagnostic value of cervical discography in the management of cervical discogenic pain. Conn Med 2000; 64:395-398.

86. Ohnmeiss DD, Guyer RD, Mason SL. The relation between cervical discographic pain responses and radiographic images. Clin J Pain 2000; 16:1-5.

87. Ransford AO, Cairns D, Mooney V. The Pain Drawing as an Aid to the Psychologic Evaluation of Patients with Low Back Pain. Spine 1976: 1:127-133.

88. Ohnmeiss DD, Vanharanta H, Guyer RD. The association between pain drawings and computed tomographic/discographic pain responses. Spine 1995; 20:729-733.

89. Ohnmeiss DD, Vanharanta H, Ekholm J. Relation between pain location and disc pathology: a study of pain drawings and CT/ discography. Clin J Pain 1999; 15:210-217.

90. Ohnmeiss DD, Vanharanta H, Ekholm J. De- gree of disc disruption and lower extremity pain. Spine 1997; 22:1600-1605.

91. O’Neill C, Kurgansky M. Subgroups of positive discs on discography. Spine 2004; 29:2134-2139.

92. Osti OL, Fraser RD. MRI and discography of annular tears and intervertebra disc degeneration. A prospective clinical comparison. J Bone Joint Surg Br 1992; 74: 431-435.

93. Parfenchuck TA, Janssen ME. A correlation of cervical magnetic resonance imaging and discography/computed tomographic discograms. Spine 1994; 19:2819-2825.

94. Parker LM, Murrell SE, Boden SD, Horton WC. The outcome of posterolateral fusion in highly selected patients with discogenic low back pain. Spine 1996; 21:1909-1916.

95. Ricketson R, Simmons JW, Hauser BO. The prolapsed intervertebral disc. The high-intensity zone with discography correlation. Spine 1996; 21:2758-2762.

96. Saifuddin A, Emanuel R, White J, Renton P, Braithwaite I, Taylor BA. An analysis of radiating pain at lumbar discography. Eur Spine J 1998; 7:358-362.

97. Saifuddin A, Braithwaite I, White J, Taylor $B A$, Renton P. The value of lumbar spine magnetic resonance imaging in the demonstration of anular tears. Spine 1998; 23: 453-457.

98. Schechter NA, France MP, Lee CK. Painful internal disc derangements of the lumbosacral spine: discographic diagnosis and treatment by posterior lumbar interbody fusion. Orthopedics 1991; 14:447-451.

99. Schellhas KP, Pollei SR, Gundry CR, Heithoff KB. Lumbar disc high-intensity zone. Correlation of magnetic resonance imaging and discography. Spine 1996; 21: 79-86.

100. Schellhas KP, Smith MD, Gundry CR, Pollei SR. Cervical discogenic pain. Prospective correlation of magnetic resonance imaging and discography in asymptomatic subjects and pain sufferers. Spine 1996; 21:300-311.

101. Schellhas KP, Garvey TA, Johnson BA Rothbart PJ, Pollei SR. Cervical diskography: analysis of provoked responses at $\mathrm{C}_{2}-\mathrm{C}_{3}, \mathrm{C}_{3}-\mathrm{C}_{4}$, and $\mathrm{C}_{4}-\mathrm{C}_{5}$. AJNR Am J Neuroradiol 2000; 21:269-275.

102. Schellhas KP, Pollei SR, Dorwart RH. Thoracic discography. A safe and reliable technique. Spine 1994; 19:2103-2109.

103. Schwarzer AC, Aprill CN, Derby R, Fortin J, Kine G, Bogduk N. The prevalence and clinical features of internal disc disruption in patients with chronic low back pain. Spine 1995; 20:1878-1883.

104. Schwarzer AC, Aprill CN, Derby R, Fortin J, Kine G, Bogduk N. The relative contributions of the disc and zygapophyseal joint in chronic low back pain. Spine 1994; 19: 801-806.

105. Shah RV, Kaye AD. Evolving concepts in the understanding of cervical facet joint pain. Pain Physician 2004; 7:295-300.
106. Siebenrock KA, Aebi M. Cervical discography in discogenic pain syndrome and its predictive value for cervical fusion. Arch Orthop Trauma Surg 1994; 113:199-203.

107. Espersen JO, Buhl M, Eriksen EF, Fode K, Klaerke A, Kroyer L, Lindeberg H, Madsen $\mathrm{CB}$, Strange $\mathrm{P}$, Wohlert L. Treatment of cervical disc disease using Cloward's technique. I. General results, effect of different operative methods and complications in 1,106 patients. Acta Neurochir (Wien) 1984; 70:97-114.

108. Heiskari M. Comparative retrospective study of patients operated for cervical disc herniation and spondylosis. Ann Clin Res 1986; 18 Suppl 47:57-63.

109. Kikuchi S, Macnab I, Moreau P. Localisation of the level of symptomatic cervical disc degeneration. J Bone Joint Surg $\mathrm{Br}$ 1981; 63B:272-277.

110. Simmons JW, Emery SF, McMillin JN, Landa D, Kimmich SJ. Awake discography. A comparison study with magnetic resonance imaging. Spine 1991; 16:S216-S221.

111. Modic MT, Steinberg PM, Ross JS, Masaryk TJ, Carter JR. Degenerative disk disease: assessment of changes in vertebral body marrow with MR imaging. Radiology 1988 ; 166:193-199.

112. Smith BM, Hurwitz EL, Solsberg D, Rubinstein D, Corenman DS, Dwyer AP, Kleiner J. Interobserver reliability of detecting lumbar intervertebral disc high-intensity zone on magnetic resonance imaging and association of high-intensity zone with pain and anular disruption. Spine 1998; 23: 2074-2080.

113. Smith SE, Darden BV, Rhyne AL, Wood KE. Outcome of unoperated discogram-positive low back pain. Spine 1995; 20:19972000.

114. Vanharanta $H$, Sachs BL, Ohnmeiss DD, Aprill C, Spivey M, Guyer RD, Rashbaum RF, Hochschuler SH, Terry A, Selby D, Stith WJ,. Mooney V. Pain provocation and disc deterioration by age. A CT/discography study in a low-back pain population. Spine 1989; 14:420-423.

115. Vanharanta H, Sachs BL, Spivey M, Hochschuler SH, Guyer RD, Rashbaum RF, Ohnmeiss DD, Mooney V. A comparison of CT/ discography, pain response and radiographic disc height. Spine 1988; 13:321324.

116. Vanharanta H, Guyer RD, Ohnmeiss DD, Stith WJ, Sachs BL, Aprill C. Spivey M, Rashbaum RF, Hochschuler SH, Videman T, Selby DK, Terry A, Mooney V. Disc deterioration in low-back syndromes. A prospective, multi-center CT/discography study. Spine 1988; 13:1349-1351.

117. Weishaupt D, Zanetti M, Hodler J, Min K, Fuchs B, Pfirrmann CW, Boos N. Painful Lumbar Disk Derangement: Relevance of Endplate Abnormalities at MR Imaging. Radiology 2001; 218:420-427.

118. Walsh TR, Weinstein JN, Spratt KF, Lehmann TR, Aprill C, Sayre H. Lumbar discography in normal subjects. A controlled, pro- 
spective study. J Bone Joint Surg Am 1990; 72:1081-1088.

119. Wetzel FT, LaRocca SH, Lowery GL, Aprill $\mathrm{CN}$. The treatment of lumbar spinal pain syndromes diagnosed by discography. Lumbar arthrodesis. Spine 1994; 19:792800.

120. Wood KB, Schellhas KP, Garvey TA, Aeppli $D$. Thoracic discography in healthy individuals. A controlled prospective study of magnetic resonance imaging and discography in asymptomatic and symptomatic individuals. Spine 1999; 24:1548-1555.

121. Yrjama M, Tervonen O, Vanharanta H. Ultrasonic imaging of lumbar discs combined with vibration pain provocation compared with discography in the diagnosis of internal anular fissures of the lumbar spine. Spine 1996; 21:571-575.

122. Zheng Y, Liew SM, Simmons ED. Value of magnetic resonance imaging and discography in determining the level of cervical discectomy and fusion. Spine 2004; 29: 2140-2145.

123. Zucherman J, Derby R, Hsu K, Picetti G, Kaiser J, Schofferman J, Goldthwaite N, White A. Normal magnetic resonance imaging with abnormal discography. Spine 1988; 13:1355-1359.

124. Deeks JJ. Systematic reviews in health care: Systematic reviews of evaluations of diagnostic and screening tests. $B M J$ 2001; 323:157-162

125. Knottnerus JA, van Weel C, Muris JW. Evaluation of diagnostic procedures. $B M$ J 2002; 324:477-480.

126. Mixter WJ, Barr JS. Rupture of the intervertebral disc with involvement of the spinal canal. New Engl J Med 1934; 211:210-215

127. Crock HV. Internal disc disruption. A challenge to disc prolapse fifty years on. Spine 1986; 11:650-653

128. Holt EP Jr. Further reflections on cervical discography. JAMA 1975; 231:613-614.

129. Holt EP Jr. The question of lumbar discography. J Bone Joint Surg Am 1968; 50:720726.

130. Holt EP Jr. Fallacy of cervical discography. Report of 50 cases in normal subjects. JAMA 1964; 188:799-801.

131. Kirkaldy-Willis WH, Hill RJ. A more precise diagnosis for low-back pain. Spine 1979; 4:102-109.

132. Peterson HO. The hazards of myelography. Radiology 1975; 115:237-239

133. Pfirmann CWA, Metzdorf A, Zanetti M, Hodler J, Boos N. Magnetic resonance classification of lumbar intervertebral disc degeneration. Spine 2001; 26:1873-1878.

134. Carrino JA, Morrison WB, Parker L, Schweitzer ME, Levin DC, Sunshine JH. Spinal injection procedures: volume, provider distribution, and reimbursement in the U.S. medicare population from 1993 to 1999. Radiology 2002; 225:723-729.

135. Crock HV. A reappraisal of intervertebral disc lesions. Med J Aust 1970; 1:983-989.

136. Fujimaki A, Crock HV, Bedbrook GM. The results of 150 anterior lumbar interbody fusion operations performed by two surgeons in Australia. Clin Orthop 1982; (165):164-167.

137. Blumenthal SL, Baker J, Dossett A, Selby DK. The role of anterior lumbar fusion for internal disc disruption. Spine 1988; 13: 566-569.

138. Fraser RD. Interbody, posterior, and combined lumbar fusions. Spine 1995; 20: 167S-177S.

139. Fritzell $P$, Hagg $O$, Wessberg P, Nordwall A; Swedish Lumbar Spine Study Group. Chronic low back pain and fusion: a comparison of three surgical techniques: a prospective multicenter randomized study from the Swedish lumbar spine study group. Spine 2002; 27:1131-1141.

140. Turner JA, Deyo RA, Loeser JD, Von Korff M, Fordyce WE. The importance of placebo effects in pain treatment and research. JAMA 1994; 271:1609-1614.

141. Turner JA, Ersek M, Herron L, Haselkorn J, Kent D, Ciol MA, Deyo R. Patient outcomes after lumbar spinal fusions. JAMA 1992; 268:907-911.

142. Blumenthal SL, Ohnmeiss DD; NASS. Intervertebral cages for degenerative spinal diseases. Spine / 2003; 3:301-309.

143. Shah RV, Lutz GE, Lee J, Doty SB, Rodeo S. Intradiskal electrothermal therapy: a preliminary histologic study. Arch Phys Med Rehabil 2001; 82:1230-1237.

144. Freeman BJ, Walters RM, Moore RJ, Fraser RD. Does intradiscal electrothermal therapy denervate and repair experimentally induced posterolateral annular tears in an animal model? Spine 2003; 28:26022608.

145. Spruit M, Jacobs WC. Pain and function after intradiscal electrothermal treatment (IDET) for symptomatic lumbar disc degeneration. Eur Spine / 2002; 11:589-593.

146. Endres SM, Fiedler GA, Larson KL. Effectiveness of intradiscal electrothermal therapy in increasing function and reducing chronic low back pain in selected patients. WMJ. 2002; 101:31-34.

147. Kleinstueck FS, Diederich CJ, Nau WH, Puttlitz CM, Smith JA, Bradford DS, Lotz JC. Temperature and thermal dose distributions during intradiscal electrothermal therapy in the cadaveric lumbar spine. Spine 2003; 28:1700-1708.

148. Wassertheil-Smoller S. Mostly about screening. In Wassertheil-Smoller S (ed). Biostatistics and Epidemiology A Primer for Health and Biomedical Professionals. Springer-Verlag, New York, 2004, pp 129140.

149. Weinstein S, Obuchowski NA, Lieber ML. Clinical evaluation of diagnostic tests. $A J R$ Am J Roentgenol 2005; 184:14-19.

150. Riegelman RK. Testing a test (Section II). In Riegelmann RK (ed). Studying A Study And Testing A Test: How To Read The Medical Evidence $5^{\text {th }}$ Ed. Lippincott Williams \& Wilkins, Philadelphia, 2005, pp 137-192.

151. Yasuma T, Ohno R, Yamauchi Y. False- negative lumbar discograms. Correlation of discographic and histological findings in postmortem and surgical specimens. I Bone Joint Surg Am 1988; 70:1279-1290.

152. Quinnell RC, Stockdale HR. An investigation of artefacts in lumbar discography. $\mathrm{Br}$ J Radiol 1980; 53:831-839.

153. Merskey H, Bodguk N. Classification of Chronic Pain. Descriptions of Chronic Pain Syndromes and Definition of Pain Terms, 2nd ed. IASP Press, Seattle, 1994, pp 180181.

154. Guyer RD, McAfee PC, Hochschuler SH, Blumenthal SL, Fedder IL, Ohnmeiss DD, Cunningham BW. Prospective randomized study of the Charite artificial disc: Data from two investigational centers. Spine J 2004; 4:252S-259S.

155. Blumenthal SL, Ohnmeiss DD, Guyer R, Hochschuler S, McAfee P, Garcia R, Salib R, Yuan H, Lee C, Bertagnoli R, Bryan V, Winter R. Artificial intervertebral discs and beyond: A North American Spine Society Annual Meeting symposium. Spine J 2002; 2 : 460-463.

156. Zigler JE, Burd TA, Vialle EN, Sachs BL, Rashbaum RF, Ohnmeiss DD. Lumbar spine arthroplasty: Early results using the ProDisc II: A prospective randomized trial of arthroplasty versus fusion. J Spinal Disord Tech 2003; 16:352-361.

157. Guyer RD, Ohnmeiss DD. Intervertebral disc prostheses. Spine 2003; 28:S15-S23.

158. Finch PM, Price LM, Drummond PD. Radiofrequency heating of painful annular disruptions: one-year outcomes. I Spinal Disord Tech 2005; 18:6-13.

159. Bogduk N, Karasek M. Two-year follow-up of a controlled trial of intradiscal electrothermal anuloplasty for chronic low back pain resulting from internal disc disruption. Spine J 2002; 2:343-350.

160. Shah RV, Ericksen JJ, Lacerte M. Interventions in chronic pain management. 2. New frontiers: Invasive nonsurgical interventions. Arch Phys Med Rehabil 2003; 84: S $39-S_{44}$

161. Ercelen O, Bulutcu E, Oktenoglu T, Sasani M, Bozkus H, Cetin Saryoglu A, Ozer F. Radiofrequency lesioning using two different time modalities for the treatment of lumbar discogenic pain: a randomized trial. Spine 2003; 28:1922-1927.

162. Khot A, Bowditch M, Powell J, Sharp D. The use of intradiscal steroid therapy for lumbar spinal discogenic pain: A randomized controlled trial. Spine 2004; 29:833-837.

163. Fritzell P, Hagg O, Wessberg P, Nordwall A; Swedish Lumbar Spine Study Group. 2001 Volvo Award Winner in Clinical Studies: Lumbar fusion versus nonsurgical treatment for chronic low back pain: A multicenter randomized controlled trial from the Swedish Lumbar Spine Study Group. Spine 2001; 26:2521-2534.

164. Boswell MV, Shah RV, Everett CR, Sehgal N, McKenzie-Brown A Abdi S, Bowman RC, Deer TR, Datta S, Colson JD, Spillane WF, Smith HS, Lucas-Levin LF, Burton 
AW, Chopra P, Staats PS, Wasserman RA, Manchikanti L. Interventional Techniques in the Management of Chronic Spinal Pain: Evidence-Based Practice Guidelines. Pain Physician 2005; 8:1-48.

165. Freemont AJ, Watkins A, Le Maitre C, Baird P, Jeziorska M, Knight MT, Ross ER, O’Brien JP, Hoyland JA. Nerve growth factor expression and innervation of the painful intervertebral disc. J Pathol 2002; 197:286292.

166. Freemont AJ, Peacock TE, Goupille P, Hoyland JA, O’Brien JP, Jayson MI. Nerve ingrowth into diseased intervertebral disc in chronic back pain. Lancet 1997; 350:178181.

167. Coppes MH, Marani E, Thomeer RT, Groen GJ. Innervation of "painful” lumbar discs. Spine 1997; 22:2342- 2350.

168. Peng B, Wu W, Hou S, Li P, Zhang C, Yang Y. The pathogenesis of discogenic low back pain. J Bone Joint Surg Br 2005;87:62-67.

169. Fagan A, Moore R, Vernon Roberts B, Blumbergs $P$, Fraser R. ISSLS prize winner: The innervation of the intervertebral disc: A quantitative analysis. Spine 2003; 28 : 2570-2576.

170. Onda A, Yabuki S, Kikuchi S. Effects of neutralizing antibodies to tumor necrosis factor-alpha on nucleus pulposus-induced abnormal nociresponses in rat dorsal horn neurons. Spine 2003; 28:967-972.

171. Weiler C, Nerlich AG, Bachmeier BE, Boos N. Expression and distribution of tumor necrosis factor alpha in human lumbar intervertebral discs: A study in surgical specimen and autopsy controls. Spine 2005; 30:44- 54 .

172. Groen GJ, Baljet B, Drukker J. Nerves and nerve plexuses of the human vertebral column. Am J Anat 1990; 188:282-296.

173. Groen GJ, Baljet B, Drukker J. The innervation of the spinal dura mater: anatomy and clinical implications. Acta Neurochir (Wien) 1988; 92:39-46.

174. Treede RD, Rolke R, Andrews K, Magerl W. Pain elicited by blunt pressure: neurobiological basis and clinical relevance. Pain 2002; 98:235-240.

175. Roberts S, Eisenstein SM, Menage J, Evans $\mathrm{EH}$, Ashton IK. Mechanoreceptors in intervertebral discs. Morphology, distribution, and neuropeptides. Spine 1995 15; 20: 2645-2651.

176. Prushansky T, Dvir Z, Defrin-Assa R. Reproducibility indices applied to cervical pressure pain threshold measurements in healthy subjects. Clin J Pain 2004; 20:341347.

177. Rolke R, Andrews Campbell K, Magerl W, Treede RD. Deep pain thresholds in the distal limbs of healthy human subjects. Eur J Pain 2005; 9:39-48.

178. Clauw DJ, Williams D, Lauerman W, Dahlman M, Aslami A, Nachemson AL, Kobrine Al, Wiesel SW. Pain sensitivity as a correlate of clinical status in individuals with chronic low back pain. Spine 1999; 24: 2035-2041.
179. Giesecke T, Gracely RH, Grant MA, Nachemson A, Petzke F, Williams DA, Clauw DJ. Evidence of augmented central pain processing in idiopathic chronic low back pain. Arthritis Rheum 2004; 50:613-623.

180. Wilke H, Neef P, Hinz B, Seidel H, Claes L. Intradiscal pressure together with anthropometric data data set for the validation of models. Clin Biomech 2001; 1:S111S126.

181. Wilke HJ, Neef P, Caimi M, Hoogland T, Claes LE. New in vivo measurements of pressures in the intervertebral disc in daily life. Spine 1999; 24:755-762.

182. Bernards CM. Sophistry in medicine: lessons from the epidural space. Reg Anesth Pain Med 2005; 30:56-66.

183. Adams MA, McNally DS, Dolan P. 'Stress' distributions inside intervertebral discs. The effects of age and degeneration. Bone Joint Surg Br 1996; 78:965-972.

184. Heggeness MH, Doherty BJ. Discography causes end plate deflection. Spine 1993 15; 18:1050-1053.

185. Cooke PM, Lutz GE. Internal disc disruption and axial back pain in the athlete. Phys Med Rehabil Clin N Am 2000; 11:837865.

186. Wagner AL, Murtagh FR, Arrington JA, Stallworth D. Relationship of Schmorl's nodes to vertebral body endplate fractures and acute endplate disk extrusions. AJNR Am J Neuroradiol 2000; 21:276-281.

187. Kokkonen SM, Kurunlahti M, Tervonen O, Ilkko E, Vanharanta H. Endplate degeneration observed on magnetic resonance imaging of the lumbar spine: Correlation with pain provocation and disc changes observed on computed tomography diskography. Spine 2002; 27:2274-2278.

188. McNally DS, Shackleford IM, Goodship AE, Mulholland RC. In vivo stress measurement can predict pain on discography. Spine 1996; 21:2580-2587.

189. Lee SH, Derby R, Chen Y, Seo KS, Kim MJ. In vitro measurement of pressure in intervertebral discs and annulus fibrosus with and without annular tears during discography. Spine J 2004; 4:614-618.

190. Bogduk N. Low back pain. In Clinical Anatomy of the Lumbar Spine and Sacrum, $3^{\text {rd }}$ Ed. Churchill Livingstone, New York, 1997, pp 187-214.

191. Hurri H, Karppinen J. Discogenic pain. Pain 2004; 112:225-228.

192. O’Neill CW, Liu JJ, Leibenberg E, Hu SS, Deviren V, Tay BK, Chin CT, Lotz JC. Percutaneous plasma decompression alters cytokine expression in injured porcine intervertebral discs. Spine J 2004; 4:88-98.

193. Solovieva S, Leino-Arjas P, Saarela J, Luoma K, Raininko R, Riihimaki H. Possible association of interleukin 1 gene locus polymorphisms with low back pain. Pain 2004; 109:8-19.

194. Ala-Kokko L. Genetic risk factors for lumbar disc disease. Ann Med 2002; 34:4247.
195. Woolf CJ, American College of Physicians American Physiological Society. Pain: moving from symptom control toward mechanism-specific pharmacologic management. Ann Intern Med 2004; 140:441451.

196. Peterson CK, Bolton JE, Wood AR. A crosssectional study correlating lumbar spine degeneration with disability and pain. Spine 2000; 25:218-223.

197. Kauppila LI, Eustace S, Kiel DP, Felson DT, Wright AM. Degenerative displacement of lumbar vertebrae. A 25-year followup study in Framingham. Spine 1998; 23: 1868-1874.

198. Maigne JY, Lapeyre E, Morvan G, Chatellier G. Pain immediately upon sitting down and relieved by standing up is often associated with radiologic lumbar instability or marked anterior loss of disc space. Spine 2003; 28:1327-1334.

199. Fujiwara A, Lim TH, An HS, Tanaka N, Jeon $\mathrm{CH}$, Andersson GB, Haughton VM. The effect of disc degeneration and facet joint osteoarthritis on the segmental flexibility of the lumbar spine. Spine 2000; 25:30363044 .

200. Borenstein D. Does osteoarthritis of the lumbar spine cause chronic low back pain? Curr Rheumatol Rep 2004; 6:14-19.

201. Iguchi T, Kanemura A, Kasahara K, Kurihara A, Doita M, Yoshiya S. Age distribution of three radiologic factors for lumbar instability: probable aging process of the instability with disc degeneration. Spine 2003; 28:2628-2633.

202. Kirkaldy-Willis WH, Farfan HF. Instability of the lumbar spine. Clin Orthop Relat Res 1982; (165):110-123.

203. Matsunaga S, Ijiri K, Hayashi K. Nonsurgically managed patients with degenerative spondylolisthesis: A 10- to 18-year followup study. J Neurosurg Spine 2000; 93:194198.

204. Mulholland RC, Sengupta DK. Rationale, principles and experimental evaluation of the concept of soft stabilization. Eur Spine J 2002; 2:S198-S205.

205. Stoll TM, Dubois G, Schwarzenbach 0 . The dynamic neutralization system for the spine: a multi-center study of a novel nonfusion system. Eur Spine J 2002; 2:S170S178.

206. Melzack R. From the gate to the neuromatrix. Pain 1999; 6:S121-S126.

207. Devor M. Unexplained peculiarities of the dorsal root ganglion. Pain 1999; 6:S27S35.

208. Mackey SC, Maeda F Functional imaging and the neural systems of chronic pain. Neurosurg Clin N Am 2004; 15:269-288.

209. Borsook D, Burstein R, Becerra L. Functional imaging of the human trigeminal system: opportunities for new insights into pain processing in health and disease. J Neurobiol 2004; 61:107-125.

210. Wilder-Smith $\mathrm{CH}$, Schindler D, Lovblad K, Redmond SM, Nirkko A. Brain functional magnetic resonance imaging of rectal pain 
and activation of endogenous inhibitory mechanisms in irritable bowel syndrome patient subgroups and healthy controls. Gut 2004; 53:1595-1601.

211. Hansson PT, Dickenson AH. Pharmacological treatment of peripheral neuropathic pain conditions based on shared commonalities despite multiple etiologies. Pain 2005; 113:251-254.
212. Hansson P. Difficulties in stratifying neuropathic pain by mechanisms. Eur J Pain 2003; 7:353-357.

213. Videman T, Malmivaara A, Mooney V. The value of the axial view in assessing discograms. An experimental study with cadavers. Spine 1987; 12:299-304.

214. Bahado-Singh RO, Oz AU, Kovanci E, Deren O, Copel J, Baumgarten A, Mahoney J. New
Down syndrome screening algorithm: UItrasonographic biometry and multiple serum markers combined with maternal age. Am J Obstet Gynecol 1998; 179:1627-1631.

215. Bahado-Singh RO, Oz U, Kovanci E, Cermik D, Flores D, Copel J, Mahoney M, Cole L. New triple screen test for Down syndrome: combined urine analytes and serum AFP. J Matern Fetal Med 1998; 7:111-114. 
